\title{
"Resolution of optimization problems and construction of efficient portfolios: An application to the Euro Stoxx 50 index"
}




\section{$\Phi|R| E|A|$}

Institut de Recerca en Economia Aplicada Regional i Pública

Research Institute of Applied Economics

Universitat de Barcelona

Av. Diagonal, 690 • 08034 Barcelona

WEBSITE: www.ub.edu/irea/•CONTACT: irea@ub.edu

The Research Institute of Applied Economics (IREA) in Barcelona was founded in 2005, as a research institute in applied economics. Three consolidated research groups make up the institute: AQR, RISK and GiM, and a large number of members are involved in the Institute. IREA focuses on four priority lines of investigation: (i) the quantitative study of regional and urban economic activity and analysis of regional and local economic policies, (ii) study of public economic activity in markets, particularly in the fields of empirical evaluation of privatization, the regulation and competition in the markets of public services using state of industrial economy, (iii) risk analysis in finance and insurance, and (iv) the development of micro and macro econometrics applied for the analysis of economic activity, particularly for quantitative evaluation of public policies.

IREA Working Papers often represent preliminary work and are circulated to encourage discussion. Citation of such a paper should account for its provisional character. For that reason, IREA Working Papers may not be reproduced or distributed without the written consent of the author. A revised version may be available directly from the author.

Any opinions expressed here are those of the author(s) and not those of IREA. Research published in this series may include views on policy, but the institute itself takes no institutional policy positions. 
We assess the effectiveness of various portfolio optimization strategies (only long allocations) applied to the components of the Euro Stoxx 50 index during the period 2002-2015. The sample under study contemplates episodes of high volatility and instability in financial markets, such as the Global Financial Crisis and the European Debt Crisis. This implies a real challenge in portfolio optimization strategies, since all the methodologies used are restricted to the assignment of positive weights. We use the daily returns for the asset allocation with a three year estimation window, keeping the assets in portfolio for one year.

In the context of strategies with short-selling constraints, we contribute to the debate on whether naive diversification proves to be an effective alternative for the construction of the portfolio, as opposed to the portfolio optimization models. To that end, we analyse the out-of-sample performance of 16 strategies for the selection of assets and weights in the main stock index of the euro area. Our results suggest that a large number of strategies outperform both the naive strategy and the Euro Stoxx 50 index in terms of the profitability and Sharpe's ratio. Furthermore, the portfolio strategy based on the maximization of the diversification ratio provides the highest return and the classical strategy of mean-variance renders the highest Sharpe ratio, which is statistically different from the Euro Stoxx 50 index in the period under study.

JEL classification: C14, C61, G11

Keywords: Optimization problems; portfolio choice; investment decisions; asset allocation; econometrics; minimum-variance portfolios; robust statistics; out-of-sample performance.

Víctor Adame-García, Universidad Complutense de Madrid, Campus de Somosaguas, 28223 Madrid, Spain. E-mail:vadame@ucm.es

Fernando Fernández-Rodríguez, Universidad de Las Palmas de Gran Canaria, Campus de Tafira, 35017 Las Palmas de Gran Canaria, Spain. E-mail: fernando.fernandez@ulpgc.es Simón Sosvilla-Rivero, Complutense Institute for International Studies, Universidad Complutense de Madrid, Campus de Somosaguas, 28223 Madrid, Spain. E-mail: sosvilla@ccee.ucm.es

\section{Acknowledgements}

Simon Sosvilla-Rivero thanks the hospitality provided by the Department of Economics during a research visit at the University of Bath. 


\section{Introduction}

Markowitz $(1952,1959)$ suggested that a rational investor should choose a portfolio with the lowest risk for a given level of return instead of investing in individual assets, calling these portfolios as efficient. This approach has been the first model of portfolio selection in the literature, which is known as Markowitz's mean-variance (M-V) analysis. Although the M-V methodology has become the central base of the classical finance, leading directly to the development of the Capital Asset Pricing Model (CAPM) by Sharpe (1964), Lintner (1965) and Mossin (1966), the practical application is surrounded by difficulties due to their poor out-of-sample performance, since the expected returns are estimated based only on sample information, which results in an estimation error.

A latter approach to addressing the estimation error involves the application of Bayesian techniques, or shrinkage estimators. Jorion (1991) uses the Bayesian approach to overcome the weakness of the expected returns estimated using only sample information. More recent approaches are based on the asset pricing model (see Pástor, 2000; or Pástor and Stambaugh, 2000); and the imposition short-selling constraint rules (e.g., Frost and Savarino, 1988; Chopra, 1993; Jagannathan and Ma, 2003). Similarly, in the literature there have been proposals of introducing the minimum-variance portfolios, based on the estimation of the covariance matrix, which is not generally as sensitive to estimation error and provides a better out-of-sample performance (see Chan et al., 1999; and Jagannathan and Ma, 2003; among others). Additionally, Konno and Yamazaki (1991) proposed the mean absolute deviation (MAD) model, which is based on the Markowitz's (1959) model. The MAD model is considered as a relevant alternative to the traditional $\mathrm{M}-\mathrm{V}$ model, since it takes into account the mean absolute deviation instead of the standard deviation.

It is also common to use robust optimization techniques to overcome the problems of stochastic programming techniques (see, for example, Quaranta and Zaffaroni, 2008; DeMiguel et al., 2009; DeMiguel and Nogales, 2009; Harris and Mazibas, 2013; Allen et $a$,.. 2014a, 2014b; Xing et al., 2014.). Choueifaty and Coignard (2008) and Choueifaty et al. (2013) proposed an approach based on the portfolio with the highest ratio of diversification. In addition Qian $(2005,2006,2011)$ introduced the portfolio with equal contribution to risk, which assigns different weights to assets so that their contribution to the overall volatility of the portfolio is proportional, the properties of this strategy being analysed by Maillard et al. (2010). These methodologies aim to defend against the possible uncertainty in the parameters, given that the true values of the parameters of the statistical model are not exactly known.

In recent years, the interest of the authorities has increased considerably regarding the measurement of the effects of unexpected losses associated with extreme events in financial markets. This leads directly to improved methodologies for measurement and quantification of risk. In this sense, it is considered that the traditional $\mathrm{M}-\mathrm{V}$ framework, frequently used in the selection of efficient portfolios, should be revised to introduce more complex risk measures than the simple standard deviation, in particular risk measures based on the quantile. This is the context that explains the choice of Value at Risk (VaR) as synthetic risk measure that can express the market risk of a financial asset or portfolio (JP Morgan, 1994). Nevertheless, VaR has been the subject of strong criticism, despite the widespread use in banking supervision. VaR lacks subadditivity, 
so it is not a coherent risk measure for the general distribution of loss, and this goes against the diversification principle (see Artzner et al., 1997, 1999).

Moreover, the absence of convexity of the VaR causes considerable difficulties in portfolio selection models based on its minimization. Furthermore, the VaR has been criticized for not being able to quantify the so-called 'tail risk': the risk of a portfolio falling more than 3 standard deviations from its current price. This has led some researchers to define new risk measures such as Conditional Value at Risk (CVaR or Expected Shortfall, ES): the expected loss exceeding the VaR (see Rockafellar and Uryasev, 2000, 2002; Pflug, 2000; and Gaivoronski and Pflug, 2005, among others).

Indeed, there has been a rapid impulse in the literature about the use of $\mathrm{CVaR}$ in portfolio theory. Additionally, the $\mathrm{CVaR}$ has the mathematical advantage that can be minimized using linear programming methods. A simple description of the approach to minimize $\mathrm{CVaR}$ and $\mathrm{CVaR}$ constrained optimization problems can be found in Chekhlov et al. (2000). Krokhmal et al. (2002) compared the CVaR and Conditional Drawdown-at-Risk (CDAR) approaches for minimal risk portfolios in some hedge funds. Agarwal and Naik (2004), and Giamouridis and Vrontos (2007) compared the traditional $\mathrm{M}-\mathrm{V}$ approach with $\mathrm{CVaR}$ portfolios built using hedge funds strategies.

In the context of strategies with short-selling constraints, the objective of this paper is to compare the out-of-sample performance of the naive strategy regarding various models for the construction of efficient portfolios. It should be noted that there exists an ongoing debate in the literature on whether the gains from optimization are reduced by estimation errors or uncertainty in the parameters, which influence in the portfolio optimization process. In this sense, there is no consensus in the literature on whether the naive diversification is more effective than other portfolio strategies, specially when there are not short-selling constraints (see recent contributions in this area, such as DeMiguel et al., 2009; Tu and Zhou, 2011; Kirby and Ostdiek, 2012; Allen et al., 2014a, 2014b and Adame et al., 2016).

For this purpose, we considered a number of optimization models: (a) the classical M-V approach (Markowitz, 1952, 1959), the minimum variance approach (Jagannathan and Ma, 2003) and the MAD model proposed by Konno and Yamazaki (1991); (b) robust optimization techniques, as the most diversified portfolio (see Choueifaty and Coignard, 2008; Choueifaty et al., 2013, among others) and the equally weighted risk contributions portfolios (see Qian, 2005, 2006, 2011); (c) portfolio optimization based on CVaR (Rockafellar and Uryasev, 2000, 2002; Alexander and Baptista, 2004; Quaranta and Zaffaroni, 2008); (d) functional approach based on risk measures such as the 'Maximum draw-down' (MaxDD), the 'Average draw-down' (AvDD), and the 'Conditional draw-down at risk' (CDAR), all proposed by Chekhlov et al. (2000, 2005), as well as the Conditional draw-down at risk, 'MinCDaR' (see Chekhlov et al., 2005; or Kuutan, 2007); (e) Young's (1998) minimax optimization model, based on minimizing risk and optimizing the risk/return ratio; (f) an application of Copula theory to build the minimum tail dependent portfolio, where the variance-covariance matrix is replaced by lower tail dependence coefficient (see Frahm et al., 2005; Fischer and Dörflinger, 2006; and Schmidt and Stadtmüller, 2006); (g) a defensive approach to systemic risk by beta strategy ('Low Beta'), where the beta coefficient $(\beta)$ is used to assess systemic risk of an asset in the CAPM model (see, e. g., Sharpe, 1964; Lintner, 1965; Mossin, 1966), as 
related volatility of an asset, market, and the correlation between them. To conclude, it should be pointed out that we impose a short-selling constraint in the models.

Following DeMiguel et al. (2009), it is of paramount importance to compare the results of different methodologies with the 'naive diversification of $1 / \mathrm{N}$ ', which assigns equal weight to the risky assets. The $1 / \mathrm{N}$ strategy has proved as a difficult alternative to beat, specially when there are not short-selling constraints, the context where DeMiguel et al. (2009) work. Therefore, we propose an efficiency analysis of the various methodologies compared with the naive diversification of $1 / \mathrm{N}$ and the main euro area stock index (the Euro Stoxx 50 index)

For the evaluation of the out-of-sample performance, we use five statistical criteria. The first one is the Sharpe ratio as a measure of the excess return (Sharpe, 1994). To test if the Sharpe ratio of two strategies is statistically different, we obtain the $p$-value of the difference, using the approach suggested by Jobson and Korkie (1981), after making the correction proposed by Memmel (2003). Similarly, we calculate the diversification ratio as a measure of the degree of portfolio diversification (see, e. g., Choueifaty and Coignard, 2008; and Choueifaty et al., 2013); and the concentration ratio, which is simply the normalized Herfindahl-Hirschmann index (Hirschman, 1964); VaR as synthetic risk measure that can express the market risk of a financial asset or portfolio, and the CVaR or ES, as a coherent risk measure that takes into account the 'tail risk'.

As for the data, we used a sample of the daily values of the stocks into the Euro Stoxx 50 index. The prices are adjusted for dividend and these are taken from Datastream. The sample period, running from 3 January 1999 to 31 December 2015, encompasses two episodes of turmoil in financial markets: the Global Financial Crisis, which began in 2008; and the European Sovereign Debt Crisis (2010-2011).

The Euro Stoxx 50 index is a reference index of the euro area. The Index is developed by Stoxx Limited, which is a joint venture between the firms Deutsche Börse, Dow Jones \& Company and SWX Swiss Exchange. The most relevant fact of this index is that it brings together the 50 largest companies among the 19 supersectors in terms of market capitalization in 11 member countries ${ }^{1}$. This gives it a very high degree of diversity or diversification. It is an index weighted by stock market capitalization, so not all companies that form it have the same representation. It is the main European index and one of the largest in the world in terms of the market capitalization of the companies that compose it. In addition, the Euro Stoxx 50 index index is often used as a barometer of the euro area's economy.

The Euro Stoxx 50 index has been the subject of a large number of studies. For example, Dunis et al. (2010) apply a statistical arbitrage technique of pairs trading to high-frequency equity data and compare its profit potential to the standard sampling frequency of daily closing prices to the constituent shares of the Euro Stoxx 50 index. Brechmann and Czado (2013) develop a flexible factor model based on the R-vine to analyse the dependency structure between the main European shares represented in the Euro Stoxx 50 index and discuss the passive and active management of the portfolio using models of the vine copulas. Moreover, Xidonas and Mavrotas (2014) manage to

1 These countries are Austria, Belgium, Germany, Finland, France, Italy, Ireland, Luxembourg, Netherlands, Portugal and Spain. 
co-assess a set of sophisticated real-world non-convex investment policy limitations, such as cardinality constraints, buy-in thresholds, transaction costs, particular normative rules, etc., where the validity of the attempt is verified through an illustrative application on the Euro Stoxx 50 index.

We used the daily returns with an estimate window equal to three years, 756 days. Therefore, the portfolios have been built for a sample size $\mathrm{N}_{\mathrm{t}}=756$ and the results have been evaluated out of sample for the next period $\mathrm{N}_{t+1}$ (see Table 1). We considered only those stocks that have shown continuity within the index during the estimation period. We show in Table 1 the number of assets in each period, while in Table A1 in the Annex we report the actual asset considered in each time period.

[Insert Table 1 around here]

The rest of the paper is organized as follows. In Section 2, we describe the various methodologies used for the portfolio construction. In Section 3, we explain the methodology for the performance evaluation. In Section 4, we show the results against the Euro Stoxx 50 index and the naive strategy of $1 / \mathrm{N}$. In Section 5, we present some concluding remarks.

\section{Methodological description}

In this Section we offer a brief description of the different portfolio strategies assessed in this paper. Table 2 offers a list of the asset-allocation models under study.

[Insert Table 2 around here]

\subsection{Mean-variance (M-V) portfolio}

The efficient frontier of mean-variance is defined as the set of values $\left(\mu_{i}, \sigma_{i}{ }^{2}\right)$ that resolves the following multi-objective optimization problem:

$$
\begin{gathered}
\max w^{T} \mu, \\
\min w^{T} \sum w \\
\text { s.t. } w^{T} \mathbf{1}=1 .
\end{gathered}
$$

Where $w^{T}$ is the $(N \times 1)$ vector of weights and $\Sigma$ denotes the variance-covariance matrix of asset returns with elements outside the diagonal and $\sigma_{i j}$ and $\sigma_{i}^{2}$ the $i$ th element of the main diagonal.

Each point on the efficient frontier $\left(\mu_{i}, \sigma_{i}^{2}\right)$ corresponds to an efficient portfolio $T$ where the investor gets a maximum return for a given level of risk $\sigma_{i}$. The efficient frontier of mean-variance reflects the relationship between return and risk, introducing the trade-off concept of risk-return in the financial markets. Therefore, it describe the level of return $\mu_{i}$ given a risk exposure $\sigma_{i}$, or seen from a reverse perspective, the lower 
variability $\sigma_{i}$ for a return level $\mu_{i}$ (Markowitz, 1952, 1959).

A risk-averse rational investor will make an investment decision on the efficient frontier when the risky asset returns exhibit a multivariate normal distribution or if her utility function is quadratic. The best choice will reflect the investor's willingness to trade off risk against expected return. To solve efficiently the problem of quadratic optimization with two objectives described above, the problem can be converted into a quadratic optimization problem for different levels of return $\mu_{i}$ (Tsao, 2010).

$$
\begin{aligned}
& \min w^{T} \sum w, \\
& \text { s.t. } \quad w^{T} \mu=\mu_{i}, \\
& \text { s.t. } \quad w^{T} \mathbf{1}=1, \\
& \text { s.t. } \quad w^{T} \geq 0 .
\end{aligned}
$$

The expected return and the variance of the portfolio are $w^{T} \mu$, and $w^{T} \sum w$, respectively. In this article, we solve the above quadratic optimization problem and establish an expected return $\mu_{i}$ equal to the average return on the assets that are considered in the optimization problem. We have also included a short-selling restriction such that $w^{T} \geq 0$.

\subsection{Minimum-variance (GMV) portfolio}

We use the previous optimization problem to assign the weights $w$ to each asset in the minimum-variance portfolio, but not including the restriction on returns, $w \mu=\mu_{i}$.

$$
\begin{aligned}
& \min w \sum w, \\
& \text { s.t. } \quad w \mathbf{1}=1, \\
& \text { s.t. } \quad w \geq 0 .
\end{aligned}
$$

We obtain the portfolio that provides the minimum variance $\sigma_{i}^{2}$, given any return $\mu_{i}$ in the efficient frontier of mean-variance. In contrast to the mean-variance portfolio, the minimum variance weight vector does not depend of the expected return on assets (see Jagannathan and Ma, 2003, for a study of the properties).

\subsection{Mean absolute deviation (MAD) portfolio}

Konno and Yamazaki (1991) proposed the MAD as an alternative to the traditional model of $\mathrm{M}-\mathrm{V}$ where the mean absolute deviation is taken into account instead of the standard deviation. 
They suggest that the applicability of the Markowitz portfolio optimization model entails certain difficulties because it is a quadratic programming problem, since seconddegree programming problems are more difficult to solve and to apply than linear problems. In addition, the size of the covariance matrix for the resolution of the portfolio selection model is very large and difficult to estimate. Solving the linear program is simpler, inasmuch as the number of functional constraints remains constant regardless of the number of assets included in the model. An optimal portfolio derived from the MAD model may contain up to $N$ assets, this difference can be substantial when $N$ is above 1,000 .

The MAD model considers the deviation below the rate of average return as a variance, therefore, it is not required to calculate the covariance matrix between the assets, which is generally considered as a drawback of the Markowitz model. Moreover, this model can work without setting assumptions about the uncertain parameter distributions and it is possible to update the model easily when adding new data.

$$
\begin{aligned}
& \min \sum_{j=1}^{n} r_{j} x_{j} \geq \rho C, \\
& \text { s.t. } \sum_{j=1}^{n} r_{j} x_{j} \geq \rho C, \\
& \text { s.t. } \sum_{j=1}^{n} x_{j}=C,
\end{aligned}
$$

s.t. $0 \leq x_{j} \leq u_{j} . \quad j=1,2, \ldots, N$.

The problem can be reformulated using the auxiliary variable $y_{t}$

$$
\begin{gathered}
\min \frac{1}{T} \sum_{j=1}^{n} y_{t} \\
\text { s.t. } y_{t}+\sum_{j=1}^{n}\left(r_{j t}-r_{j}\right) x_{j} \geq 0, t=1, \ldots, T, \\
\text { s.t. } y_{t}-\sum_{j=1}^{n}\left(r_{j t}-r_{j}\right) x_{j} \geq 0, t=1, \ldots, T, \\
\text { s.t. } \sum_{j=1}^{n} r_{j} x_{j} \geq \rho C,
\end{gathered}
$$




$$
\begin{gathered}
\text { s.t. } \sum_{j=1}^{n} x_{j}=C, \\
\text { s.t. } 0 \leq x_{j} \leq u_{j}, \quad j=1,2, \ldots, N .
\end{gathered}
$$

where $x_{j}$ denotes the units of the asset $j$ which will be included in the portfolio, $y_{t}$ is the deviation below the rate of average return in the period $t, T$ is the length of the time horizon. Each period over the time horizon is represented by $t(t=1,2, \ldots, T)$. The parameter $\rho$ refers to the minimum rate of return required by an investor. The rate of return on the asset $j$ Is represented by a random variable $R_{j}$. The variable $r_{j}$ is the expected performance, $E\left[R_{j}\right]$, of asset $j$, so that the return of the asset $j$ in the period $t$ is expressed by $r_{j t}$. Also, $u_{j}$ is the maximum amount of asset $j ; C$ and $N$ refer to the total expenditure of the portfolio and the total number of assets, respectively (see Moon and Yao, 2011).

\subsection{Naive diversification $(1 / \mathrm{N})$}

Several studies confirm the existence of some investors who distribute their wealth through naive diversification strategy. Typically they invest in a few assets alike (see Benartzi and Thaler, 2001; and Huberman and Jiang, 2006). This fact does not prove that the naive diversification is a good strategy, since investors may select a portfolio that is not within the efficient frontier, or she may choose the wrong point in it. Both situations involve a cost, where the second cost is the most important (see Brennan and Torous, 1999).

The naive strategy involves a weight distribution $w_{j}=1 / N$ for all risky assets in the portfolio. This strategy ignores the data and does not involve any estimation or optimization. DeMiguel et al. (2009) suggest that the expected returns are proportional to total risk instead systematic risk.

\subsection{Equal risk contributed (ERC) portfolio}

The portfolios built under the criterion of minimum variance and equally weighted (naive strategy $1 / N$ ) are of great interest because they are not based on the expected average returns and therefore they are supposed to be robust. Although the minimumvariance portfolios generally have the disadvantage of a high concentration ratio, it can be limited through diversification (see Qian, 2005).

Here is where the equal risk contributed portfolio is located, which assigns different weights to assets so that the contribution of these on total portfolio volatility is proportional. Therefore, the diversification is achieved by a weight vector, which is characterized by a distribution of less concentrated portfolio. The ERC portfolio was introduced in the literature by Qian $(2005,2006,2011)$ and their properties were analyzed by Maillard et al. (2010). 
Maillard et al. (2010) showed that when it comes to the standard deviation of the portfolio, the ERC solution takes an intermediate position between a minimum-variance portfolio and equally weighted portfolio. Therefore, the resulting portfolio is similar to a minimum-variance portfolio under additional diversification restrictions.

Let $M\left(w_{i}, \ldots, w_{N}\right)$ denote a measure of homogeneous risk, which is a function weight $w_{i}$ of each asset in the portfolio. By Euler's theorem $M=\alpha \sum_{i=1}^{N} w_{i} \frac{\partial M}{\partial w_{i}}$, where $\alpha$ is the degree of homogeneity of $M$. This leads us to consider the contribution to the risk of asset $i$ to be defined in the form

$$
C_{i} M_{w \in \Omega}=w_{i} \frac{\partial M_{w \in \Omega}}{\partial w_{i}}
$$

The measure of risk $M_{w \in \Omega}$ can be the standard deviation of the portfolio, the value at risk or the expected shortfall if the degree of homogeneity is one. The portfolio risk is equal to the sum of the risk contributions. If we introduce the formula for the standard deviation portfolio $\sigma(w)=\sqrt{w^{\prime} \Sigma w}$ to $M_{w \in \Omega}$, then the partial derivatives in the above equation are given by

$$
\frac{\partial \sigma(w)}{\partial w_{i}}=\frac{w_{i} \sigma_{i}^{2}+\sum_{i \neq j}^{N} w_{i} \sigma_{i j}}{\sigma(w)} .
$$

These $N$ partial derivatives are proportional to the $i$ th row of $(\Sigma w)_{i}$, so the problem for the ERC portfolio with a short-sale constraints and a budget constraint is

$$
\begin{gathered}
E R C: w_{i}\left(\sum \mathrm{w}\right)_{i}=w_{j}\left(\sum \mathrm{w}\right)_{j}, \forall i, j \\
0 \leq w_{i} \leq 1 \\
w^{\prime} \mathbf{i}=1 .
\end{gathered}
$$

where $\mathbf{i}$ is an $(N \times 1)$ vector of ones. The optimal solution of ERC is valid if the value of the objective function is zero, and this only occurs when all contributions are equal risk. A closed-form solution can only be derived under the assumption that all asset pairs share the same correlation coefficient. Under this assumption, the optimal weights are determined by the ratio of the inverse volatility of the $i$ th asset and the average of the inverse asset volatilities (see Pfaff, 2013).

\subsection{Most diversified portfolio (MDP)}

Choueifaty and Coignard (2008) and Choueifaty et al. (2013) studied the theoretical and empirical properties of portfolios when the diversification is used as criterion. To do this, they established a measure for which the degree of diversification for a long portfolio could be evaluated. We define the diversification ratio (DR) to any portfolio $P$ as

$$
D R(P)=\frac{w^{\prime} \sigma}{\sqrt{w^{\prime} \sum w}} .
$$


The numerator is the weighted average volatility of the individual assets, divided by the volatility of the portfolio. This relationship has a lower limit of one in the case of a portfolio composed only by an asset. Choueifaty et al. (2013) show that the portfolio characterized by a highly concentrated or with an asset returns very correlated would qualify as being poorly diversified, so that

$$
D R(P)=\frac{1}{\sqrt{(\rho+C R)-\rho C R}} .
$$

where $\rho$ denotes the volatility-weighted average correlation and $C R$ is the volatilityweighted concentration ratio. The DR only depends on the volatility-weighted average correlations in the case of a naive allocation.

Choueifaty et al. (2013) established the conditions for the most diversified portfolio by introducing a set of synthetic assets that share the same volatility, such that

$$
D(S)=\frac{S^{\prime} \sum_{S}}{\sqrt{S^{\prime} V_{S} S}} .
$$

where $S$ is a portfolio composed by synthetic assets, and $V_{S}$ is the covariance matrix of synthetic assets. If we have to $S^{\prime} \sum_{S}=1$, then to maximize $D(S)$ is equivalent to maximize $\frac{1}{\sqrt{S^{\prime} V_{S} S}}$ under $\Gamma_{S}$ restrictions. $V_{S}$ is equal to the correlation matrix $C$ of initial assets, so that to maximize the diversification ratio is equivalent to minimize

$$
S^{\prime} C S \text {. }
$$

Thus, if the assets have the same volatility, the diversification ratio is maximized by minimizing $w^{\prime} C w$. Therefore, The target function matches with the minimum-variance portfolio, although it is used the correlation matrix.

The impact of asset volatility is lower in the more diversified portfolio compared with the minimum-variance portfolio (see Pfaff, 2013). The weights are retrieved by intermediate vector rescaling weights with standard deviations of asset returns. The optimal weight vector is determined in two steps: first, an allocation is determined that yields a solution for a least correlated asset mix. This solution is then inversely adjusted by the asset volatilities, and later, the weights of the assets are adjusted inversely by their volatilities.

\subsection{Minimum tail-dependent (MTD) portfolio}

Minimum tail-dependent portfolio is determined through replacing the variancecovariance matrix by the lower tail dependence coefficients matrix. In that sense, the lower tail of the correlation coefficient measures the dependence of the relationship between the asset returns when these are extremely negative. It is possible to find a scheme with various nonparametric estimators for minimum tail-dependent portfolio in Frahma et al. (2005), and Dörflinger Fischer (2006) and Schmidt and Stadtmüller (2006). 
The copula notion was introduced by Sklar (1959). Sklar's theorem states that there is a $\mathrm{C}$ function, called copula, which establishes the functional relationship between the joint distribution and their marginal one-dimensional. Formally, let $x=\left(x_{1}, x_{2}\right)$ be a two-dimensional random vector with joint distribution function $F\left(x_{1}, x_{2}\right)$ and marginal distributions $F_{i}\left(x_{i}\right), i=1,2$; there will be a copula $C\left(u_{1}, u_{2}\right)$ such that

$$
F\left(x_{1}, x_{2}\right)=P\left(X_{1}<x_{1}, X_{2}<x_{2}\right)=C\left(F_{1}\left(x_{1}\right), F_{2}\left(x_{2}\right)\right) \text {. }
$$

Moreover, Sklar's theorem also provides that if $F_{i}$ are continuous, then the copula $C\left(u_{1}, u_{2}\right)$ is unique. An important feature of copula is that it allows different degrees of dependency on the tail. The upper tail dependence $\left(\lambda_{U}\right)$ exists when there is a positive likelihood that positive outliers are given jointly; while the lower tail dependence $\lambda_{L}$, exists when there is a negative likelihood that negative outliers are given jointly (see Boubaker and Sghaier, 2013). Thereby, we define the lower tail dependence coefficient as follows

$$
\lambda_{L}=\lim _{u \rightarrow 0} \frac{C(u, u)}{u}
$$

This limit can be interpreted as a conditional probability; therefore, the lower tail dependence coefficient is limited in the range $[0,1]$. The limits are: for an independent copula $\left(\lambda_{L}=0\right)$, and for a co-monotonic copula $\left(\lambda_{L}=1\right)$. Nonparametric estimators for $\lambda_{L}$ are derived from empirical copula.

For a given sample paired observations $N,\left(X_{1}, Y_{1}\right), \ldots,\left(X_{N}, Y_{N}\right)$, with order statistics $X_{(1)} \leq X_{(2)} \cdots \leq X_{(N)}$ and $Y_{(1)} \leq Y_{(2)} \ldots \leq Y_{(N)}$, the empirical copula is defined as

$$
C_{N}\left(\frac{i}{N}, \frac{j}{N}\right)=\frac{1}{\mathrm{~N}} \sum_{\mathrm{l}=1}^{\mathrm{N}} I\left(\mathrm{X}_{\mathrm{l}} \leq \mathrm{X}_{(\mathrm{i})} \wedge \mathrm{Y}_{\mathrm{l}} \leq \mathrm{Y}_{\mathrm{j}}\right) .
$$

with $i, j=1, \ldots, N$ and $I$ is the indicator function, which has a value of 1 if the condition in parentheses is true. $C_{N}$ takes a zero value for $i, j=0$.

In the literature, there are several consistent and asymptotically efficient estimators of $\lambda_{\mathrm{L}}$, although this depend on a threshold parameter $k$, that is the number of statistical order. It is very important to select $k$ correctly in order to estimate the lower tail dependence coefficient, if $k$ is too small, this will result in an inaccurate estimation and a high bias.

For example, the following nonparametric method for estimating of $\lambda_{\mathrm{L}}$ is derived from a mixture of co-monotonous copula and independent copula. The lower tail dependence coefficient is the weight parameter between the two copulas (see Pfaff, 2013). So that

$$
\lambda_{\mathrm{L}}(N, k)=\frac{\sum_{i=1}^{k}\left(C_{N}\left(\frac{i}{N}, \frac{i}{N}\right)-\left(\frac{i}{N}\right)^{2}\right)\left(\left(\frac{i}{N}\right)-\left(\frac{i}{N}\right)^{2}\right)}{\sum_{i=1}^{k}\left(\frac{i}{N}-\left(\frac{i}{N}\right)^{2}\right)^{2}} .
$$




\subsection{CVaR portfolio}

Rockafellar and Uryasev (2000) have advocated for CVaR as a useful measure of risk. Pflug (2000) showed that CVaR is a coherent risk measure with a number of attractive and desirable properties such as monotonicity, translational invariance, positive homogeneity, further $\mathrm{CVaR}$ satisfies subadditivity and it is convex.

$\mathrm{CVaR}$ is proposed as a method to calculate the market risk arising as a complementary measure to VaR. CVaR is applicable to non-symmetric distributions loss, which takes into account risks beyond the VaR. Furthermore, CVaR accomplishes convexity property with what is possible to identify a global optimum point.

The upper conditional value at risk $\left(\mathrm{CVaR}^{+}\right)$is defined as expected losses exceed strictly the VaR; and the lower conditional value at risk $\left(\mathrm{CVaR}^{-}\right)$is defined as weakly losses exceeding the $\mathrm{VaR}$ (greater or equal losses to $\mathrm{VaR}$ ). Thus, the conditional value at risk is equal to the weighted average $\mathrm{VaR}$ and $\mathrm{CVaR}^{+}$. CVaR quantifies the excess losses of $\mathrm{VaR}$ and acts as an upper bound for the $\mathrm{VaR}$. Therefore, portfolios with low $\mathrm{CVaR}$ also have a low VaR. A number of documents apply $\mathrm{CVaR}$ to portfolio optimization problems (see, for example, and Uryasev Rockafellar, 2000, 2002; Andersson et al., 2001; Alexander and Baptista, 2004; and Rockafellar et al. 2006).

In terms of selection of portfolios, $\mathrm{CVaR}$ can be represented as a minimization problem of nonlinear programming with an objective function given as

$$
\min _{w, v} \frac{1}{n a} \sum_{i=1}^{n}\left[\max \left(0, v-\sum_{j=1}^{m} w_{j} r_{i, j}\right]\right. \text {. }
$$

where $v$ is the quantile $\alpha$ of the distribution. In the discrete case, Rockafellar and Uryasev (2000) show that its possible to convert this problem a linear programming problem by introducing auxiliary variables, so that

$$
\begin{gathered}
\min _{w, d, v} \frac{1}{n a} \sum_{i=1}^{n} d_{i}+v, \\
\sum_{j=1}^{m} w_{j} r_{i, j}+v \geq-d_{i}, \forall \in\{1, \ldots, n\}, \\
\sum_{j=1}^{m} w_{j} \mu_{j}=C, \\
\sum_{j=1}^{m} w_{j}=1, \\
w_{j} \geq 0, \forall j \in\{1, \ldots, n\},
\end{gathered}
$$




$$
d_{i} \geq 0, \forall i \in\{1, \ldots, n\}
$$

where $v$ represents the $\mathrm{VaR}$ in the coverage ratio, $\alpha$ and $d_{i}$ are deviations below the $\mathrm{VaR}$ (see Allen et al., 2014b). If the CVaR is minimized, simultaneously, the VAR also will be minimized.

\subsection{Optimal draw-down portfolios}

They are portfolio optimization problems that try to achieve weight solutions with respect to the portfolio's draw-down. This kind of optimization was proposed by Chekhlov et al. (2000, 2005). The task of finding optimal portfolio allocations with respect to draw-down is of considerable interest to asset managers, as it is possible to avoid, somehow, large withdrawals and/or loss of revenue management.

The draw-down of a portfolio at time $t$ is defined as the difference between the maximum uncompounded portfolio value prior to $t$ and its value at $t$. Formally, denote by $\mathrm{W}(w, t)=\mathrm{y}_{\mathrm{t}}^{\prime} \mathrm{W}$ the uncompounded portfolio value at time $t$, with $w$ the portfolio weights for the $N$ assets included in it, and $y_{t}$ is the accumulated returns. Then the draw-down, $\mathbb{D}(w, t)$, is difined as

$$
\mathbb{D}(w, t)=\max _{0 \leq \tau \leq 1}\{W(w, \tau)\}-W(w, t) .
$$

Chekhlov et al. (2000) deducted three functional measures of risk: maximum drawdown (MaxDD), average draw-down (AvDD) and conditional draw-down at risk (CDaR). CDaR is dependent on the chosen confidence level $\alpha . \mathrm{CDaR}$ is a measure of functional risk and not a risk measure as in the case of $\mathrm{CVaR}$. The limiting cases of this family of risk functions are MaxDD and AvDD.

$$
\operatorname{CDaR}(w)_{\alpha}=\min _{\zeta}\left\{\zeta \frac{1}{(1-\alpha) T} \int_{0}^{T}[\mathbb{D}(w, t)-\zeta]^{+} d t\right\} .
$$

where $\zeta$ is a threshold value for the draw-downs, so that only $(1-\alpha) T$ observations exceed this value.

For $\alpha \rightarrow 1, \mathrm{CDaR}$ approaches to the maximum draw-down: $\operatorname{CDaR}(w)_{\alpha \rightarrow 1}=$ $\operatorname{MaxDD}(w)=\max _{0 \leq t \leq T}\{\mathbb{D}(w, t)\}$. The AvDD result for $\alpha=0$ is $\operatorname{CDaR}(w)_{\alpha=0}=$ $\operatorname{AvDD}(w)=(1 / T) \int_{0}^{T} \mathbb{D}(w, t) d t$.

The portfolio optimization is expressed in discrete terms and the objective is defined as maximizing the annualized average return of the portfolio, (see Pfaff, 2013).

$$
R(w)=\frac{1}{d C} y_{T}^{\prime} w
$$


where $d$ is the number of years in the time interval $[0, T]$. In short, we consider the three functional risk measures, MaxDD, AvDD and $\mathrm{CDaR}$, proposed by Chekhlov et al. $(2000,2005)$. Furthe, we consider the minimization of CDaR.

$$
\begin{gathered}
\operatorname{MaxDD}=\arg \max _{w, u} R(w)=\frac{1}{d C} y_{T}^{\prime} w \\
u_{k}-y_{k}^{\prime} w \leq v_{1} C \\
u_{k} \geq y_{k}^{\prime} w \\
u_{k} \geq u_{k-1} \\
u_{0}=0 .
\end{gathered}
$$

where $\mathbf{u}$ denotes a $(T+1 \times 1)$ vector of slack variables in the program formulation, in effect, the maximum portfolio values up to time period $k$ with $1 \leq k \leq T$. When the portfolio is optimized with regard to limiting of the average draw-down, only the first set of inequality constraints needs to be replaced with the discrete analogue of the mean draw-down expressed in continuous time as indicated above (see Pfaff, 2013), result to

$$
\begin{gathered}
\operatorname{AvDD}=\arg \max _{w, u} R(w)=\frac{1}{d C} y_{T}^{\prime} w, \\
\frac{1}{T} \sum_{k=1}^{T}\left(u_{k}-y_{k}^{\prime} w\right) \leq v_{2} C, \\
u_{k} \geq y_{k}^{\prime} w, \\
u_{k} \geq u_{k-1}, \\
u_{0}=0 .
\end{gathered}
$$

For the $\mathrm{CDaR}$ linear programming problem is necessary to introduce two additional auxiliary variables, the threshold draw-down value $\zeta$ dependent on the confidence level $\alpha$, and the $(T \times 1)$ vector $\mathbf{z}$, representing the weak threshold exceedances; so that

$$
\begin{gathered}
\mathrm{CDaR}=\arg \max _{w, u, z, \zeta} R(w)=\frac{1}{d C} y_{T}^{\prime} w, \\
\zeta+\frac{1}{(1-\alpha) T} \sum_{k=1}^{T} z_{k} \leq v_{3} C, \\
z_{k} \geq u_{k}-y_{k}^{\prime} w-\zeta, \\
z_{k} \geq 0, \\
u_{k} \geq y_{k}^{\prime} w
\end{gathered}
$$




$$
\begin{gathered}
u_{k} \geq u_{k-1}, \\
u_{0}=0 .
\end{gathered}
$$

The minimization of CDaR (see Cheklov et al., 2005; and Kuutan, 2007) can be obtained similarly to the conditional value at risk (CVaR) through linear optimization, but we have to introduce auxiliary variables

$$
\begin{gathered}
\operatorname{MinCDaR}=\arg \min y+\frac{1}{(1-\alpha) T} \sum_{t=1}^{T} z_{k}, \\
z_{k} \geq u_{k}-r_{p}(w, t)-y, \\
z_{k} \geq 0, \\
u_{k} \geq r_{p}(w, t), \\
u_{k} \geq u_{k-1} .
\end{gathered}
$$

where $y$ is the threshold value of the accumulative distribution function $D(w, t)$, and $z_{k}, u_{k}$ are auxiliary variables.

The limitations $u_{k} \geq r_{p}(w, t)$, and $u_{k} \geq u_{k-1}$ replace linearly the higher value of the portfolio till the moment $t: \max \left\{r_{p}(w, t)\right\}$. The first constraint ensures that $u_{k}$ is always higher or at least equal to the portfolio accumulated return in the moment $k$, and the second constraint ensures that $u_{k}$ is always higher or at least equal to the previous value (see Kuutan, 2007). Before of the optimization process, $y$ is a free variable, after of the optimization process it is the $C D a R_{\alpha}$ for the MinCDaR portfolio. Thus, if we minimize the function $H_{\alpha}(w, y)$, we simultaneously obtain both values (see Unger, 2014).

\subsection{Minimum tail-dependent portfolio based in Clayton copula and low beta strategy.}

The minimum tail-dependent is derived from a Clayton copula. The Clayton copula belongs to the family of Archimedean copula, its one of the most used in the literature (see Clayton, 1978). An Archimedean generator, or generator, is a continuous decreasing function $\psi:[0, \infty] \rightarrow[0,1]$ which complies $\psi(0)=1, \psi(\infty):=$ $\lim _{t \rightarrow \infty} \psi(t)=0$, and that is strictly decreasing on $[0, \inf \{t: \psi(t)=0\}]$. The set of all functions is denoted by $\Psi$.

An Archimedean generator $\psi \in \Psi$ is called strict if $\psi(t)<0$ for all $t \in[0, \infty]$. A ddimensional copula $C$ is called Archimedean (see Hofert and Scherer, 2011) if it allows the representation

$$
C(\mathrm{u})=\mathrm{C}(\mathrm{u} ; \psi):=\psi\left(\psi^{-1}\left(\mathrm{u}_{1}\right)+\cdots+\psi^{-1}\left(\mathrm{u}_{\mathrm{d}}\right)\right), \mathrm{u} \in \mathrm{I}^{\mathrm{d}} .
$$


for some $\psi \in \Psi$ with inverse $\psi^{-1}:[0,1] \rightarrow[0, \infty]$, where $\psi^{-1}(0):=\inf \{\mathrm{t}: \psi(\mathrm{t})=0\}$. There are different notations for Archimedean copula. A bivariate Clayton copula can be presented so that

$$
C\left(u_{1}, u_{2}\right)=\psi^{-1}\left(\psi\left(u_{1}\right)+\psi\left(u_{2}\right)\right)=\left(u_{1}^{-\delta}+u_{2}^{-\delta}-1\right)^{1 / \delta} .
$$

The Clayton copula has the minimum tail-dependent. The coefficient is calculated according to $\lambda_{l}=2^{-1 / \delta}$. For the bivariate Clayton copula, the following simplifications are given

$$
\begin{aligned}
& \hat{\delta}=\frac{2 \hat{\rho} \tau}{1-\hat{\rho} \tau} . \\
& \hat{\theta}=\frac{1}{1-\hat{\rho} \tau} .
\end{aligned}
$$

where $\hat{\rho} \tau$ is the empirical Kendall rank correlation (see, for example, Genest and Favre, 2007).

In addition, we implemented the strategy of lower beta coefficient ("Low Beta"), beta $(\beta)$ is the coefficient used to evaluate systemic risk of an asset in the CAPM model, (see Sharpe, 1964; Lintner, 1965; and Mossin, 1966), and it relates the volatility of an asset, market, and the correlation between them. We select assets whose volatility is less than the reference market, in absolute terms, for the construction of the beta portfolio. The process to build the portfolio can be summarized so that, we get the beta coefficients of each asset such that

$$
\beta_{i}=\frac{\operatorname{Cov}\left(R_{i}, R_{b}\right)}{\sigma_{b}^{2}}
$$

where the numerator represents the covariance between assets $i$ and the market $b$, and the denominator is the variance of the market.

Then, we select those assets whose $\beta$ coefficients and coefficients of tail dependence are below their respective medians. Finally, we get the weights by applying an inverse logarithmic scale (this application can be seen in Pfaff, 2013). Both strategies are referred to as defensive relative to the market (benchmark), as they are aimed at minimizing systemic risk.

\subsection{Minimax portfolios based on risk minimization and optimization of the risk/return ratio}

The Minimax model (see Young, 1998) aims to minimize the maximum expected loss, thus its a very conservative criterion. Formally, when it applied to the selection of portfolios, given $N$ assets and $t$ periods, the model can be presented as a linear programming problem, such that 


$$
\begin{gathered}
\min _{M_{p, w}} M_{p} \\
M_{p}-\sum_{j=1}^{m} w_{j} r_{i, j} \leq 0, \forall i=\{1, \ldots, n\}, \\
\sum_{j=1}^{m} w_{j} \mu_{J}=C \\
\sum_{j=1}^{m} w_{j}=1, \\
w_{j} \geq 0, \forall j \in\{1, \ldots, n\} .
\end{gathered}
$$

where $M_{p}$ is the target value to minimize, which represents the maximum loss of the portfolio given a weight vector $w, C$ is a certain minimum level of return, and $\mu$ denote the forecast for the returns vector of $m$ values. In principle, Minimax is consistent with the theory of expected utility in the limit based on an investor very risk averse. Furthermore, the minimax model is a good approximation to the mean-variance model when the asset returns follow a multivariate normal distribution. If we draw the portfolios set for different levels of $C$ (using an equality rather than inequality), its possible to generate the frontier portfolio from which the optimal risk portfolio can be chosen. Its possible to estimate the optimal risk/return using fractional programming as it is described in Charnes and Cooper (1962), and more recently in Stoyanov et al., (2007). The Minimax linear programming problem can be reformulated, so that

$$
\begin{gathered}
\min _{M_{p, w b}} M_{p} \\
M_{p}-\sum_{j=1}^{m} w_{j} r_{i, j} \leq 0, \forall i=\{1, \ldots, n\} \\
\sum_{j=1}^{m} w_{j} \mu_{J}=1 \\
\sum_{j=1}^{m} w_{j}=b \\
b \geq 0
\end{gathered}
$$

where $b$ is the multiplier cofficient added to the optimization problem as result of transformation of the risk/return problem. More details can be found in Charnes and Cooper (1962) for linear programing, and in Dinkelbach (1967) for non-linear programing. We use two types of Minimax optimization: the first optimization is based on risk minimization, and the second optimization is based on the risk/return ratio. 


\section{Methodology for evaluating performance}

For the evaluation of out-of-sample performance, we take the series of daily prices of the assets that enter into the portfolio in the period $t+1$ subject to the allocation of the weights $w$, which have been obtained through the optimization process at time $t$.

$$
R V_{p}=\sum\left(w i_{t} * p i_{t_{+1}}\right)
$$

We obtain the real value of the portfolios $R V_{p}$ by this procedure, where they are treated as a single asset, and we calculate five measures for statistical comparison between the portfolio strategies ${ }^{2}$ : Value at Risk (VaR), Value at Conditional Risk (CVaR), Sharpe ratio, diversification ratio and concentration ratio.

\subsection{Value at risk (VAR) and conditional value at risk (CVaR)}

As mentioned earlier, $\mathrm{VaR}$ is a measure of synthetic risk that can express the market risk of a financial asset or portfolio. In general terms, $\mathrm{VaR}$ is the maximum potential loss that a financial asset may suffer with a certain probability for a certain period of tenure. JP Morgan tried to establish a market standard by RiskMetrics in 1994 (JP Morgan, 1994).

For a confidence level $\alpha \in(0,1), \mathrm{VaR}$ is defined as the smallest number $l$ such that the probability of loss $L$ is not greater than $1-\alpha$ for greater losses that $l$. This value corresponds to the quantiles of loss distribution, and it can be formally expressed as

$$
V a R_{\alpha}=\inf \{l \in \mathbb{R}: \mathrm{P}(L>l) \leq 1-\alpha\}=\inf \left\{l \in \mathbb{R}: F_{L}(l) \geq \alpha\right\},
$$

where $F_{L}$ is the distribution function of the losses (see Pfaff, 2013).

The expected shortfall risk measure (ES o CVaR) arises due to deficiencies that VaR shows. CVaR was introduced by Artzner et al. (1997, 1999); Rockafellar and Uryasev (2002) showed that CVaR is a consistent measure of risk and may also take into consideration the "tail risk".

$\mathrm{CVaR}$ is defined for a type I error $\alpha$ as

$$
E S_{\alpha}=\frac{1}{1-\alpha} \int_{\alpha}^{1} q_{u}\left(F_{L}\right) d u,
$$

where $q_{u}\left(F_{L}\right)$ is the quantile function of loss distribution $F_{L}$. Therefore ES can be expressed in $\mathrm{VaR}$ terms such that

\footnotetext{
2 In addition, we include the total return and annualized return of each $\mathrm{z}$ strategy. Total return $=$ $\left(\frac{F V_{Z}-I V_{Z}}{I V_{Z}}\right) \times 100 \% ;$ Annualized return $=\left[\left(F V_{Z} / I V_{Z}\right)^{1 / N}-1\right] \times 100 \%$.
} 


$$
E S_{\alpha}=\frac{1}{1-\alpha} \int_{\alpha}^{1} \operatorname{VaR}_{u}(L) d u,
$$

ES can be interpreted as the VaR average in the range $(1-\alpha, 1)$.

\subsection{Sharpe ratio}

We calculate the out of sample annualized Sharpe ratio for each strategy $z$. Sharpe ratio is defined as the sample mean of out-of-sample excess returns over the risk-free asset $\hat{\mu}_{\mathrm{z}}$, divided by their sample standard deviation $\widehat{\sigma}_{\mathrm{z}}$, such that

$$
\text { Sharpe. } R=\frac{\hat{\mu}_{z}}{\hat{\sigma}_{z}}
$$

To test the statistical independence of the Sharpe ratios for each strategy with respect to benchmark, we calculate the p-value of the difference, using the approach suggested by Jobson and Korkie (1981) after making the correction pointed out in Memmel (2003), and recently applied in DeMiguel et al. (2009). So that, given two portfolios $a$ and $b$, with mean $\hat{\mu}_{a}, \hat{\mu}_{b}$, variance $\hat{\sigma}_{a}, \hat{\sigma}_{b}$, and covariance $\hat{\sigma}_{a, b}$ about a sample of size $N$, its checked by the test statistic $\hat{z}_{J K}$, the null hypothesis that $H_{0}: \hat{\mu}_{a} / \hat{\sigma}_{a}-\hat{\mu}_{b} / \hat{\sigma}_{b}=0$. This test is based on the assumption that income is distributed independently and identically (IID) in time following a normal distribution, (see Jobson and Korkie, 1981; and Memmel, 2003).

\subsection{Diversification ratio (DR) and concentración ratio (CR)}

We define the DR of any portfolio $P$ as follows

$$
D R(P)=\frac{w^{\prime} \sigma}{\sqrt{w^{\prime} \sum w}} .
$$

The numerator is the weighted average volatility of the single assets, divided by the portfolio volatility (portfolio standard deviation). From the above equation is derived the following expression, such that

$$
D R(P)=\frac{1}{\sqrt{(\rho+C R)-\rho C R}},
$$

where $\rho$ denotes the volatility-weighted average correlation and CR is the volatilityweighted concentration ratio. The parameter $\rho$ is defined as

$$
\rho=\frac{\sum_{i \neq j}^{N}\left(w_{i} \sigma_{i} w_{j} \sigma_{j}\right) \rho_{i j}}{\sum_{i \neq j}^{N}\left(w_{i} \sigma_{i} w_{j} \sigma_{j}\right)} .
$$

The CR is the normalized Herfindahl-Hirschmann index (see Hirschman, 1964) 


$$
C R(P)=\frac{\sum_{i=1}^{N}\left(w_{i} \sigma_{i}\right)^{2}}{\left(\sum_{i=1}^{N} w_{i} \sigma_{i}\right)^{2}}
$$

\section{Empirical results}

Our analysis is based on a rolling window approach of size $N=756$ daily returns. Therefore, we used a total of 3 years of daily returns to estimate the necessary parameters for the implementation of the strategies considered. These estimated parameters are then used to determine the optimal allocations of each risky asset inside the portfolio. We use these weights to obtain the return in the following year $Y_{t}$, where $t=2002, \ldots, 2015$; This process continues until the end of the data is reached. Consequently, a total of 14 portfolios have been released for each methodology implemented. Finally, we compare the out-of-sample results obtained for the various portfolio strategies. For that, we show the results of the five measures for statistical comparison between the portfolio strategies, contained in the previous section. The portfolio strategies results are compared with the Euro Stoxx 50 index and the naive strategy of $1 / N^{3}$.

In the first and second columns of Table 3, we present the Total Return and the Annual Return of each strategy for the period 2002-2015. The value at risk and the conditional value at risk (1 day) appear in the third and fourth columns, respectively. The Sharpe ratio and the $p$-value of each strategy, including the Euro Stoxx 50 index, are shown in the fifth column. We also include the $p$-value of the difference for each strategy with respect to Euro Stoxx 50 index. In the last two columns, six and seven, we report the diversification and concentration ratios, respectively. Additionally, Figure 1 shows the returns by year of the Euro Stoxx 50 index and the $1 / N$, MDP, M-V and CVaR portfolios during the years 2002 to 2015 .

[Insert Table 3 around here]

\subsection{Out-of-sample performance: 2002-2015}

The period under study is characterized by episodes of high volatility (large losses and gains) and episodes of relative calm. In most years, the performance of portfolio strategies closely matches the Euro Stoxx 50 index; In 2015, all portfolios provide positive returns, except the AvDD strategy and the Euro Stoxx 50 index.

The Euro Stoxx 50 index rarely yields negative annual returns (4 out of 14 years analyzed). Neverthless, these are very important since they overcome on average the positive returns generated in the "good years". The year 2002 was extremely negative for the Euro Stoxx 50 index and for the naive strategy of 1/N, with losses in both cases exceeding $37 \%$. However, the rest of the strategies did not obtain losses as high as those mentioned above (for example, the CVaR portfolio renders a loss of only $-0.72 \%$ ), although all of them closed in negative. Something similar occurs in 2008, the

\footnotetext{
3 Table A2 of the Annex offers the summary statistics of Euro Stoxx 50 index and 16 portfolios during the sample period.
} 
beginning of the Global Financial Crisis, in which the Euro Stoxx 50 index closed with an extremely negative loss $(-44.37 \%)$, but in this case, the majority of strategies did show losses close to those of the index. On the contrary, the Euro Stoxx 50 index achieved significant gains in the years 2006, 2012 and 2013, although it is always overcomed by a large number of strategies, the-exception being 2013, when 2 out of the 16 strategies considered are able to overcome the index (see Table 4).

[Insert Table 4 around here]

From these findings, it can be seen that extremely negative events (large losses) have a greater effect and the extremely positive events (large gains) are more smooth on the Euro Stoxx 50 index compared to the rest of portfolio strategies (see Table A2 and Figure 1), although there exist some exceptions. In addition, there are several strategies that, in some cases, obtain returns higher than $40 \%$, when the maximum return provided by the index or the naive diversification does not exceed the $22 \%$ and $28 \%$, respectively.

\section{[Insert Figure 1 around here]}

Regarding the total return of the portfolios, six strategies obtain a total return greater than $230 \%$, to which must be added five other strategies that show a return higher than $150 \%$. Among them, the MDP portfolio stands out, generating a total return of $271.4 \%$, followed by the M-V strategy (with a return of 253.8\%) and the R-Minimax, CVaR and GMV portfolios, all of them with a return more than $240 \%$. On the other hand, the AvDD portfolio is the only strategy that renders a negative return during the period ($51.5 \%)$, besides the Euro Stoxx 50 index (-13.1\%). Although the 1/N strategy provides a $39.1 \%$ positive return, it is the lowest yielding strategy after the AvDD portfolio. The high values of the returns reported in Table 3 must be taken with caution, because no transaction costs are imputed to our strategies.

The most diversified portfolio (MDP) is the only strategy that provides a anual return higher than 9.5\%. The M-V, R-Minimax, CVaR and GMV portfolios generate an annual return higher than $9 \%$. A total of 14 out of 15 portfolio strategies outperform the naive $1 / \mathrm{N}$ strategy (2.39\%), although it is behaviour is not bad compared to the Euro Stoxx 50 (-1.00\% in annualized terms).

The VaR and the CVaR (95\%) at one day fluctuate quite intensely during the period analyzed, both for the Euro Stoxx 50 index and for the strategies under evaluation. In years of low volatility, that can be considerd as transition between episodes of great instability, the $\mathrm{VaR}$ and $\mathrm{CvaR}$ are near to the values of $1.0 \%-1.5 \%$ and $1.5 \%-2.0 \%$, respectively (except for the AvDD strategy).

However, when there is turbulence in the financial markets, the VaR and CVaR increases considerably, the VaR and CVaR at one day for the Euro Stoxx 50 index in 2008 stood at $4.21 \%$ and $5.23 \%$, respectively. In contrast to 2005 , where the one-day $\mathrm{VaR}$ and $\mathrm{CVaR}$ for Euro Stoxx 50 index stood at $1.05 \%$ and $1.33 \%$, respectively (see Tables 5 and 6). All strategies report a $\mathrm{VaR}$ and a CVaR lower than the Euro Stoxx 50 index $(2.455 \%$ and $3.081 \%$ ), with the sole exception of the AvDD strategy. It is no surprise that the M-V portfolio stands out as the one that bears the lowest values of VaR and CvaR (1.815\% and 2.287\%), followed by the MAD and the CVaR strategies. The 
naive strategy of $1 / \mathrm{N}$ has a $\mathrm{VaR}$ of $2.336 \%$ and a CVaR of $2.935 \%$, quite high since a total of eight strategies do not overcome the threshold of a VaR to a day greater than $2.0 \%$ or CvaR greater to $2.5 \%$.

[Insert Tables 5 and 6 around here]

In 2002 and 2008, the Euro Stoxx 50 index and most strategies registered the most negative values in the Sharpe ratios. In this respect, the Euro Stoxx 50 index render a Sharpe ratio of -0.998 in 2002 and of -1.113 in 2008. In 2004, unlike the Euro Stoxx 50 index, the naive $1 / \mathrm{N}$ strategy and the ERC strategy, the remaining portfolio strategies report a Sharpe ratio in no case lower than 2.30, being the year where higher yield per unit of risk is obtained. The years 2005 and 2013 are especially noteworthy, as the Euro Stoxx 50 index achieves a Sharpe ratio that exceeds 14 out of the 16 strategies (2005) and 12 out of the 16 strategies (2013). This suggests that the Euro Stoxx 50 index shows in 2005 and 2013 a better performance compared to all the strategies under consideration (see Table 7).

\section{[Insert Table 7 around here]}

Eight strategies obtain an annualized Sharpe ratio greater than or equal to 0.4. The M-V portfolio stands out with a Sharpe ratio of 0.509 , followed by the CVaR, GMV and MDP portfolios with $0.485,0.484$ and 0.482 , respectively. In contrast, the AvDD portfolio is the only one strategy reporting a negative Sharpe ratio $(-0.167)$, appart from the Euro Stoxx 50 index (-0.041). In this sense, 15 out of the 16 proposed strategies render a annualized Sharpe ratio positive and higher than the Euro Stoxx 50 index. Given the $p$-value, 10 strategies generate Sharpe ratios that are significant, that is, the Sharpe ratio of these differ statistically from the Sharpe ratio of the Euro Stoxx 50 index. Among them are not the naive strategy of $1 / \mathrm{N}$ and the ERC portfolio (combination of naive strategy and minimum variance model). Additionally, 14 strategies render a Sharpe ratio higher than the naive strategy of $1 / \mathrm{N}$, where 9 of them differ statistically from the Sharpe ratio of $1 / \mathrm{N}$ portfolio (see Table 7).

Considering the diversification ratio per year, the fluctuation that it undergoes in the strategies under evaluation is quite high. In 2004 and 2005, a large number of portfolios reach the highest ratios of diversification. In contrast, in 2010 and 2011, the portfolios formed render the lowest diversification ratio (see Table 8). Since the number of assets in the portfolios has increased, this is only explained by an intensification in the correlation between returns on financial assets. This can be inferred paying attention to the performance of the portfolio of $1 / \mathrm{N}$, which is built with all assets (see Table A6 in the Annex). This fact is widely investigated in recent papers as Moldovan (2011), for the New York, London and Tokyo index; and in Ahmad et al. (2013), for the contagion between financial markets.

[Insert Table 8 around here]

The MDP, Clayton (MTD) and MTD strategies show the highest ratios of diversification, the first one standing out with a ratio of 1.595. In addition, the MDP (more diversified) portfolio also has a high Sharpe ratio, which highlights the possibility of obtaining high Sharpe ratios and at the same time a considerable degree of diversification. Besides the portfolios already mentioned, six other strategies that also 
overcome the ratio of diversification obtained by the naive strategy of $1 / \mathrm{N}$ (1.410): Beta, MAD, GMV, ERC, M-V and CVaR. On the other hand, the AvDD portfolio (1.059) is the strategy that provides a the lowest diversification ratio (see Table 9).

[Insert Table 9 around here]

The concentration ratio can be related to the cost of building the portfolio, as it decreases when the number of assets increases in the portfolio, but this not ensure a greater degree of diversification. In the concentration ratio, the number of assets in the portfolio plays a crucial role, hence the portfolios based on naive diversification are the ones with the lowest concentration ratio, the $1 / \mathrm{N}$ portfolio with 0.022 and the ERC portfolio with 0.023 . These are followed by the Beta portfolio (0.059) and the two portfolios based on the lower tail dependence, Clayton (MTD) and MTD, with 0.055 and 0.071, respectively. On the other hand, the AvDD, MaxDD, CDaR95 and MinCDaR95 portfolios, based on Draw-Down, provide the highest concentration ratios, with the AvDD portfolio standing out with an average value of 0.880 (see Table 10).

\section{[Insert Table 10 around here]}

In Figure 2, we show the accumulated wealth of several porfolios constructed with the weights provided by our strategies. As mentioned before, these weights are estimated the first day of each year and maintained for the rest of the year. It is noticeable the poor performance, during the period 2002-2015, of the Euro Stoxx 50 index and the naive strategy of $1 / \mathrm{N}$ with respect to the other four methodologies considered (those with a Sharpe ratio greater than 0.48 ). Recall that no transaction costs have been considered.

\section{[Insert Figure 2 around here]}

Regarding to the Euro Stoxx 50 index, its differences with respect to the portfolios began to be relevant from the very beginning of the period (2002), although the greatest divergence is reached in 2015, since at the end of the Euro Stoxx 50 index closed with profitability $-13.10 \%$, when all other strategies, except for the $1 / \mathrm{N}$ strategy, registered an accumulated revaluation greater than $240 \%$ (suggesting an annual return equal to or greater than $9.20 \%$ ). With respect to the $1 / \mathrm{N}$ naive strategy, the accumulated wealth generated by this strategy is very much in line with the evolution of the Euro Stoxx 50 index, at least until the middle of 2009. However, from that year, the performance of the $1 / \mathrm{N}$ portfolio begins to differ from the evolution of the index, allowing the portfolio of $1 / \mathrm{N}$ to obtain a total return for the period of $39.10 \%$, although considerably lower than that of the MDP portfolio with a total revaluation of $271.4 \%$ (see Figure 2).

\section{Concluding remarks}

In this paper, we have empirically examined the performance of 16 asset allocation models in the main stock index of the euro area (the Euro Stoxx 50 index), in the framework of no-short-selling condition. We have compared the total returns, Sharpe ratios, $\mathrm{VaR}$ and $\mathrm{CVaR}$, and the diversification and concentration ratios of each portfolio strategy. We have analysed the performance for the daily returns over a sample of 14 years (2002-2015), whose purpose is to test the robustness of the results in periods of high and low correlations between assets and with a market 
In terms of total return, it might be highlighted the performance of the most diversified portfolio (MDP), followed by the mean-variance portfolio, the R-Minimax portfolio, the $\mathrm{CVaR}$ portfolio and the minimum-variance portfolio in terms of high profitability. Whithout considering transaction cost, all of them achieved a return more than $240 \%$, in contrast to the performance of naive diversification (39.10\%) and Euro Stoxx 50 index $(-13.10 \%)$. The behaviour of the naive strategy of $1 / \mathrm{N}$ seems to replicate that of the index during the years 2002 to 2009. As of 2009, it is observed that the behavior of the $1 / \mathrm{N}$ strategy experienced some improvement, allowing it to render an annualized return of $2.39 \%$.

We have found that, from the statistical point of view, the Sharpe ratios of the minimum-variance strategy or the most diversified portfolio are higher compared with those associated with the naive strategy of $1 / \mathrm{N}$ and the Euro Stoxx 50 index for the period 2002-2015. In this period, all the models for asset allocation, except one of them (AvDD), obtain a Sharpe ratio higher than the Euro Stoxx 50 index. Although only ten turn out to be statistically different from this one. We show that it is possible to outperform the Euro Stoxx 50 index in terms of profitability, Sharpe ratio and lower $\mathrm{VaR}$ and $\mathrm{CVaR}$, since 15 out of the 16 portfolio strategies considered corroborate it. In addition, we have focused on the debate on whether naive diversification is more effective than portfolio optimization models, where it should be noted that 14 models manage to beat the naive strategy of $1 / \mathrm{N}$ in profitability, Sharpe ratio (being 9 out of 14 statistically significant), lower $\mathrm{VaR}$ and $\mathrm{CVaR}$, and a total of 9 also provide a higher ratio of diversification.

Furthermore, our empirical results indicate that there are several strategies that do not depend on the expected assets return to assign weights (such as the GMV, the CVaR, the MDP and the MTD strategies) that are also able to overcome the naive strategy of $1 / \mathrm{N}$. Nevertheless, the Markowitz mean-variance portfolio with short-selling constraint is found to be the strategy that provides the highest Sharpe ratio (0.509) in the time period analysed (2002-2015). Our fidings suggest that the strategies that render a high return are also very diversified, so there is a positive relationship between diversification and profitability. It seems that in the Euro Stoxx 50 index, which is composed of the companies with the largest capitalization, it is important to take into account the correlation between the assets in order to select those less correlated with each other, not forgetting other parameters that influence in the optimization process.

In view of the encouraging results of this paper, we suggest that the mean-variance portfolio with short-selling constraint and the most diversified portfolio (MDP) could be used, at least as a first reference, when analysing the behaviour of the main stock market in the euro area.

All in all, the results of our analysis contrasts with those presented in DeMiguel, Garlappi, and Uppal (2009) and Allen et al. (2014a), although the latter were obtained permiting short-selling positions and we did not. These differences would be explained by two facts; the first one is that we use daily data and DeMiguel monthly one. The second reason is the use by them of short-selling positions; as Jobson and Korkie (1981), among others, point out, the lure of elegant analytical solutions provided by unrestricted mean-variance optimization could lead to investment irrelevant and misleading solutions. 
Our findings are in line with those of Kirby and Ostdiek (2012) and Allen et al. (2014b) for the hedge fund index, as well as the results reported by Adame et al. (2016) in a similar study for the main Spanish stock index (Ibex 35). Thus, although in all empirical works the results obtained have to be taken with some degree of caution (since they are based on a particular index over a certain time period), our findings lead us to infer that the naive strategy of $1 / \mathrm{N}$ can provide good results if it is compared with the benchmark. Nevertheless, the naive strategy of $1 / \mathrm{N}$ is always exceded by several portfolio optimization models.

We consider that the results presented in this paper should be of value to portfolio managers, risk strategists and insurers in assessing the risk-return profile of stocks. 


\section{References}

Adame, V. M., Fernández-Rodríguez, F., \& Sosvilla-Rivero, S. (2016). Portfolios in the Ibex 35 before and after the Global Financial Crisis. Applied Economics, 48, 38263847.

Agarwal, V., \& Naik, N. Y. (2004). Risks and portfolio decisions involving hedge funds. Review of Financial Studies, 17, 63-98.

Ahmad, W., Sehgal, S., \& Bhanumurthy, R. N. (2013). Eurozone crisis and BRIICKS stock markets: Contagion or market Interdependence? Economic Modelling, 33, 209225.

Alexander, G. J., \& Baptista, A. M. (2004). A comparison of Var and Cvar constraints on portfolio selection with the mean-variance model. Management Science, 50, 12611273.

Allen, D., McAleer, M., Peiris, S., \& Singh, A. (2014a). European market portfolio diversification strategies across the GFC. Discussion Paper TI 14-134/III, Tinbergen Institute, Amsterdam.

Allen, D., McAleer, M., Peiris, S., \& Singh, A. (2014b). Hedge fund portfolio diversification strategies across the GFC. Discussion Paper TI 14-151/III, Tinbergen Institute, Amsterdam.

Andersson, F., Mausser, H., Rosen, D., \& Uryasev, S. (2001). Credit risk optimization with conditional value-at-risk criterion. Mathematical Programming, 89, 273-291.

Artzner, P., Delbaen, F., Eber, J. \& Heath, D. (1997). Thinking coherently. Risk, 10, 6871.

Artzner, P., Delbaen, F., Eber, J.-M., \& Heath, D. (1999). Coherent measures of risk. Mathematical Finance, 9 (3), 203-228.

Benartzi, S., \& Thaler, R. H. (2001). Naive diversification strategies in defined contribution saving plans. American Economic Review, 91,79-98.

Boubaker, H., \& Sghaier, N. (2013). Portfolio optimization in the presence of dependent financial returns with long memory: A copula based approach. Journal of Banking and Finance, 37, 361-377.

Brechmann, E. C., \& Czado, C. (2013). Risk management with high-dimensional vine copulas: An analysis of the Euro Stoxx 50. Statistics \& Risk Modeling, 30, 307-342.

Brennan, M. J., \& Torous, W. N. (1999). Individual decision making and investor welfare. Economic Notes, 28, 119-143.

Chan, L. K., Karceski, J. \& Lakonishok, J. (1999). On portfolio optimization: Forecasting covariances and choosing the risk model. Review of Financial Studies, 12, 937-974. 
Charnes, A., \& Cooper, W. W. (1962). Programming with linear fractional functionals. Naval Research Logistics Quarterly, 9, 181-186.

Chekhlov, A., Uryasev, S. P. \& Zabarankin, M. (2000). Portfolio optimization with drawdown constraints. Research Report 2000-5, Department of Industrial and Systems Engineering, University of Florida, Gainesville.

Chekhlov, A., Uryasev, S. \& Zabarankin, M. (2005). Drawdown measure in portfolio optimization. International Journal of Theoretical and Applied Finance, 8, 13-58.

Chopra, V. K. (1993). Improving optimization. The Journal of Investing, 2, 51-59.

Choueifaty, Y., \& Coignard, Y. (2008). Toward maximum diversification. The Journal of Portfolio Management, 35, 40-51..

Choueifaty, Y., Froidure, T. \& Reynier, J. (2013). Properties of the most diversified portfolio. Journal of Investment Strategies, 2, 49-70.

Clayton, D. G. (1978). A model for association in bivariate life tables and its application in epidemiological studies of familial tendency in chronic disease incidence. Biometrika, 65, 141-151.

DeMiguel, V., \& Nogales, F. J. (2009). Portfolio selection with robust estimation. Operations Research, 57, 560-577.

DeMiguel, V., Garlappi, L., \& Uppal, R. (2009). Optimal versus naive diversification: How inefficient is the 1/N portfolio strategy? Review of Financial Studies, 22, 19151953.

Dinkelbach, W. (1967). On nonlinear fractional programming. Management Science, 13, 492-498.

Dunis, C. L., Giorgioni, G., Laws, J., \& Rudy, J. (2010). Statistical arbitrage and highfrequency data with an application to Eurostoxx 50 equities. Mimeo, Liverpool Business School, Liverpool.

Fischer, M. J., \& Dörflinger, M. (2006). A Note on a non-parametric tail dependence estimator. Discussion Paper 76/2006, Friedrich-Alexander-Universität ErlangenNürnberg, Chair of Statistics and Econometrics, Nürnberg.

Frahm, G., Junker, M. \& Schmidt, R. (2005). Estimating the tail-dependence coefficient: Properties and pitfalls. Insurance: Mathematics and Economics, 3, 80-100.

Frost, P. A., \& Savarino, J. E.. (1988). For better performance: Constrain portfolio weights. The Journal of Portfolio Management, 15, 29-34.

Gaivoronski, A. A., \& Pflug, G. (2005). Value-at-risk in portfolio optimization: Properties and computational approach. Journal of Risk, 7, 1-31. 
Genest, C., \& Favre, A.-C. (2007). Everything you always wanted to know about copula modeling but were afraid to ask. Journal of Hydrologic Engineering, 12, 347-368.

Giamouridis, D., \& Vrontos, I. D. (2007). Hedge fund portfolio construction: A comparison of static and dynamic approaches. Journal of Banking and Finance, 31, 199-217.

Harris, R. D., \& Mazibas, M. (2013). Dynamic hedge fund portfolio construction: A semi-parametric approach. Journal of Banking and Finance, 37, 139-149.

Hirschman, A. O. (1964). The paternity of an index. American Economic Review, 54, 761-762.

Hofert, M., \& Scherer, M. (2011). CDO pricing with nested archimedean copulas. Quantitative Finance, 11, 775-787.

Huberman, G., \& Jiang, W. (2006). Offering versus choice in 401 (K) plans: Equity exposure and number of funds. The Journal of Finance, 61, 763-801.

Jagannathan, R., \& Ma, T. (2003). Risk reduction in large portfolios: Why imposing the wrong constraints helps. The Journal of Finance, 58, 1651-1683.

Jobson, J. D., \& Korkie, B. M. (1981). Performance hypothesis testing with the sharpe and treynor measures. The Journal of Finance, 36, 889-908.

Jorion, P. (1991). Bayesian and CAPM estimators of the means: Implications for portfolio selection. Journal of Banking and Finance, 15, 717-727.

J P Morgan (1994). RiskMetrics, Technical Document. Morgan Guaranty Trust Company, New York.

Kirby, C., \& Ostdiek, B. (2012). It's all in the timing: Simple active portfolio strategies that outperform naive diversification. Journal of Financial and Quantitative Analysis, 47, 437-467.

Krokhmal, P., Palmquist, J., \& Uryasev, S. (2002). Portfolio optimization with conditional value-at-risk objective and constraints. Journal of Risk, 4, 43-68.

Kuutan, E. (2007). Portfolio optimization using conditional value-at-risk and conditional drawdown-at-risk. Doctoral dissertation, University of Toronto, Toronto.

Lintner, J. (1965). The valuation of risk assets and the selection of risky investments in stock portfolios and capital budgets. The Review of Economics and Statistics, 47, 13-37.

Maillard, S., Roncalli, T. , \& Teilletche, J. (2010). The Properties of equally weighted risk contribution portfolios. The Journal of Portfolio Management, 36, 60-70.

Markowitz, H. (1952). Portfolio selection. The Journal of Finance, 7, 77-91.

Markowitz, H. (1959). Portfolio Selection: Efficient Diversification of Investments. 
Basil Blackwall, New York.

Memmel, C. (2003)."Performance hypothesis testing with the sharpe ratio: The case of hedge funds. Finance Research Letters, 10, 196-208.

Moldovan, I. (2011). Stock markets correlation: Before and during the crisis analysis. Theoretical and Applied Economics 8, 111-122.

Moon, T., \& Yao, T. (2011). A robust mean absolute deviation model for portfolio optimization. Journal of Computers \& Operations Research, 38, 1251-1258.

Mossin, J. (1966). Equilibrium in a capital asset market. Econometrica, 34, 768-783.

Pástor, L'. (2000). “Portfolio selection and asset pricing models. The Journal of Finance, $55,179-223$.

Pástor, L., \& Stambaugh, R. F. (2000).“Comparing asset pricing models: An investment perspective. Journal of Financial Economics, 56, 335-381.

Pfaff, B. (2013). Financial Risk Modelling and Portfolio Optimization with $R$. Chichester: John Wiley \& Sons.

Pflug, G. C. (2000). Some remarks on the value-at-risk and the conditional value-atrisk, in Uryasev, S. P. (Ed.), Probabilistic Constrained Optimization, Springer US, New York, pp. 272- 281.

Qian, E. (2005). Risk Parity Portfolios: Efficient Portfolios through True Diversification. Panagora Asset Management, Boston, MA.

Qian, E. (2006). On the financial interpretation of risk contribution: Risk budgets do add up. Journal of Investment Management, 4, 1-11.

Qian, E. (2011). Risk parity and diversification. The Journal of Investing, 20, 119-127.

Quaranta, A. G., \& Zaffaroni, A. (2008). Robust optimization of conditional value at risk and portfolio selection. Journal of Banking and Finance, 32, 2046-2056.

Rockafellar, R. T., \& Uryasev, S. (2000). Optimization of conditional value-at-risk. Journal of Risk, 2, 21-42.

Rockafellar, R. T., \& Uryasev, S. (2002). Conditional value- at-risk for general loss distributions. Journal of Banking and Finance, 26, 1443-1471.

Rockafellar, R. T., Uryasev, S. \& Zabarankin, M. (2006). Generalized deviations in risk analysis. Finance and Stochastics, 10, 51-74.

Schmidt, R., \& Stadtmüller, U. (2006). Non-parametric estimation of tail dependence. Scandinavian Journal of Statistics, 33, 307-335.

Sharpe, W. F. (1964). Capital asset prices: A theory of market equilibrium under 
conditions of risk. The Journal of Finance, 19, 425-442.

Sharpe, W. F. (1994). The Sharpe ratio. The Journal of Portfolio Management, 21, 4958.

Sklar, M. (1959). Fonctions de répartition à $\mathrm{n}$ dimensions et leurs marges. Publications de l'Institut Statistique de l'Université de Paris, 8, 229-231.

Stoyanov, S. V., Rachev, S. T., \& Fabozzi, F. J. (2007). Optimal financial portfolios. Applied Mathematical Finance, 14, 401-436.

Tsao, C.-Y. (2010). Portfolio selection based on the mean-var efficient frontier. Quantitative Finance, 10, 931-945.

Tu, J., \& Zhou, G. (2011). Markowitz meets Talmud: A combination of sophisticated and naive diversification strategies. Journal of Financial Economics, 99, 204-215.

Unger, A. (2014). The Use of Risk Budgets in Portfolio Optimization. Springer Gabler, Bremen.

Xidonas, P., \& Mavrotas, G. (2014). Multiobjective portfolio optimization with nonconvex policy constraints: Evidence from the Eurostoxx 50. The European Journal of Finance, 20, 957-977.

Xing, X., Hu, J. \& Yang, Y. (2014). Robust minimum variance portfolio with 1-infinity constraints. Journal of Banking and Finance, 46, 107-117.

Young, M. R. (1998). A minimax portfolio selection rule with linear programming solution. Management Science, 44, 673-683.. 
Table 1: Number of assets by time period

\begin{tabular}{lc} 
Time period & Number of risky assets \\
\hline $02 / 01 / 2002-30 / 12 / 2002$ & 44 \\
$02 / 01 / 2003-30 / 12 / 2003$ & 45 \\
$02 / 01 / 2004-30 / 12 / 2004$ & 48 \\
$03 / 01 / 2005-30 / 12 / 2005$ & 49 \\
$02 / 01 / 2006-29 / 12 / 2006$ & 49 \\
$02 / 01 / 2007-28 / 12 / 2007$ & 49 \\
$02 / 01 / 2008-30 / 12 / 2008$ & 49 \\
$02 / 01 / 2009-30 / 12 / 2009$ & 50 \\
$02 / 01 / 2010-30 / 12 / 2010$ & 50 \\
$04 / 01 / 2011-30 / 12 / 2011$ & 50 \\
$03 / 01 / 2012-31 / 12 / 2012$ & 50 \\
$02 / 01 / 2013-31 / 12 / 2013$ & 50 \\
$02 / 01 / 2014-31 / 12 / 2014$ & 50 \\
$02 / 01 / 2015-31 / 12 / 2015$ & 50 \\
\hline
\end{tabular}

Table 2: List of asset-allocation models considered

\begin{tabular}{|c|c|c|}
\hline Methodology & Model & Abbrevation \\
\hline $\begin{array}{l}\text { 1. Naive } \\
\text { Diversification }\end{array}$ & - $\quad$ Naive strategy of $1 / N$ & $1 / \mathrm{N}$ \\
\hline 2. Classic & - Mean-variance portfolio & $\mathrm{M}-\mathrm{V}$ \\
\hline $\begin{array}{l}\text { 3. Robust } \\
\text { Portfolios }\end{array}$ & $\begin{array}{ll}\text { - } & \text { Minimum-variance portfolio } \\
\text { - } & \text { Mean absolute deviation portfolio } \\
\text { - } & \text { Most diversified portfolio } \\
\text { - } & \text { Equal risk contributed portfolio } \\
\text { - } & \text { Minimum tail-dependent portfolio }\end{array}$ & $\begin{array}{l}\text { GMV } \\
\text { MAD } \\
\text { MDP } \\
\text { ERC } \\
\text { MTD }\end{array}$ \\
\hline $\begin{array}{l}\text { 4. CVaR } \\
\text { Portfolio }\end{array}$ & - Conditional value at risk portfolio & CVaR \\
\hline $\begin{array}{l}\text { 5. Draw-down } \\
\text { Portfolios }\end{array}$ & $\begin{array}{ll}\text { - } & \text { Maximum draw-down portfolio } \\
\text { - } & \text { Average draw-down portfolio } \\
\text { - } & \text { Conditional draw-down at risk }(95 \%) \\
\text { - } & \text { Minimum conditional draw-down at risk }(95 \%)\end{array}$ & $\begin{array}{l}\text { MaxDD } \\
\text { AvDD } \\
\text { CDaR95 } \\
\text { MinCDaR95 }\end{array}$ \\
\hline $\begin{array}{l}\text { 6. Minimax } \\
\text { Portfolios }\end{array}$ & $\begin{array}{l}\text { - } \quad \text { Minimax based on risk minimization } \\
\text { - } \quad \text { Minimax based on the risk/return ratio }\end{array}$ & $\begin{array}{l}\text { R-Minimax } \\
\text { O-Minimax }\end{array}$ \\
\hline $\begin{array}{l}\text { 7. Defensive } \\
\text { Portfolios }\end{array}$ & $\begin{array}{l}\text { - Minimum tail-dependent with Clayton copula } \\
\text { - } \quad \text { Low beta portfolio }\end{array}$ & $\begin{array}{l}\text { Clayton (MTD) } \\
\text { Beta }\end{array}$ \\
\hline
\end{tabular}


Table 3: Summary of main results, 2002-2015

\begin{tabular}{|c|c|c|c|c|c|c|c|}
\hline Portfolios & $\begin{array}{c}\text { Total } \\
\text { Return }\end{array}$ & $\begin{array}{l}\text { Annual } \\
\text { Return }\end{array}$ & $\begin{array}{l}\text { VaR 95\% } \\
1 \text { day }\end{array}$ & $\begin{array}{l}\text { CVaR 95\% } \\
1 \text { day }\end{array}$ & $\begin{array}{l}\text { Annualized Sharpe } \\
\text { ratio ( } p \text {-value) }\end{array}$ & $\begin{array}{l}\text { Diversification } \\
\text { ratio }\end{array}$ & $\begin{array}{c}\text { Concentration } \\
\text { ratio }\end{array}$ \\
\hline Euro Stoxx 50 & $-13.1 \%$ & $-1.00 \%$ & 2.455 & 3.081 & $-0.041(1.000)$ & --- & --- \\
\hline $1 / \mathrm{N}$ & $39.1 \%$ & $2.39 \%$ & 2.336 & 2.935 & $0.101(0.429)$ & 1.410 & 0.022 \\
\hline $\mathrm{M}-\mathrm{V}$ & $253.8 \%$ & $9.45 \%$ & 1.815 & 2.287 & $0.509(0.015)^{* *}$ & 1.436 & 0.163 \\
\hline GMV & $243.0 \%$ & $9.20 \%$ & 1.860 & 2.342 & $0.484(0.038)^{* *}$ & 1.471 & 0.166 \\
\hline MAD & $181.0 \%$ & $7.66 \%$ & 1.819 & 2.290 & $0.413(0.070)^{*}$ & 1.483 & 0.156 \\
\hline MDP & $271.4 \%$ & $9.82 \%$ & 1.993 & 2.510 & $0.482(0.035)^{* *}$ & 1.595 & 0.105 \\
\hline ERC & $66.0 \%$ & $3.69 \%$ & 2.161 & 2.715 & $0.169(0.256)$ & 1.464 & 0.023 \\
\hline MTD & $224.8 \%$ & $8.78 \%$ & 1.927 & 2.427 & $0.446(0.025)^{* * *}$ & 1.577 & 0.071 \\
\hline CVaR & $243.7 \%$ & $9.22 \%$ & 1.859 & 2.341 & $0.485(0.036)^{* * *}$ & 1.413 & 0.212 \\
\hline MaxDD & $148.6 \%$ & $6.72 \%$ & 3.021 & 2.651 & $0.314(0.137)$ & 1.329 & 0.308 \\
\hline AvDD & $-51.5 \%$ & $-5.04 \%$ & 2.995 & 3.788 & $-0.167(0.712)$ & 1.059 & 0.880 \\
\hline CDaR95 & $100.9 \%$ & $5.11 \%$ & 2.268 & 2.852 & $0.222(0.277)$ & 1.318 & 0.321 \\
\hline MinCDaR95 & $76.8 \%$ & $4.16 \%$ & 2.073 & 2.605 & $0.198(0.311)$ & 1.351 & 0.247 \\
\hline R-Minimax & $247.1 \%$ & $9.30 \%$ & 2.052 & 2.584 & $0.444(0.038)^{* *}$ & 1.396 & 0.210 \\
\hline O-Minimax & $231.6 \%$ & $8.94 \%$ & 2.247 & 2.829 & $0.390(0.095)^{*}$ & 1.386 & 0.268 \\
\hline Clayton (MTD) & $177.0 \%$ & $7.55 \%$ & 1.922 & 2.420 & $0.386(0.054)^{*}$ & 1.584 & 0.055 \\
\hline Beta & $190.6 \%$ & $7.92 \%$ & 1.843 & 2.321 & $0.421(0.030) * *$ & 1.534 & 0.058 \\
\hline
\end{tabular}

Table 4: Returns by years

\begin{tabular}{|c|c|c|c|c|c|c|c|c|c|c|c|c|c|c|c|c|c|}
\hline Year & Index & $1 / N$ & M-V & GMV & MAD & MDP & ERC & MTD & CVaR & MaxDD & AvDD & CDaR95 & MinCDaR95 & R-M & O-M & $\begin{array}{l}\text { Clayton } \\
\text { (MTD) }\end{array}$ & Beta \\
\hline 2002 & -37.30 & -39.08 & -5.93 & -8.02 & -7.92 & -12.93 & -33.33 & -15.11 & -0.72 & -27.22 & -30.48 & -18.72 & -16.78 & -10.23 & -10.45 & -14.00 & -14.08 \\
\hline 2003 & 15.24 & 17.26 & 16.51 & 9.70 & 9.38 & 12.53 & 14.08 & 10.38 & 9.07 & 8.03 & 9.66 & -0.50 & 1.46 & 22.72 & 7.49 & 8.99 & 8.75 \\
\hline 2004 & 6.89 & 5.52 & 30.99 & 43.83 & 43.25 & 40.55 & 14.34 & 26.14 & 44.93 & 50.66 & 55.75 & 54.57 & 32.36 & 35.91 & 40.85 & 31.22 & 28.59 \\
\hline 2005 & 20.50 & 23.45 & 26.83 & 9.23 & 10.14 & 9.15 & 19.52 & 11.50 & 7.73 & 0.43 & -1.83 & 0.327 & 3.64 & 17.19 & 8.13 & 12.11 & 15.22 \\
\hline 2006 & 14.30 & 18.24 & 46.14 & 46.37 & 45.40 & 42.29 & 24.03 & 36.94 & 43.52 & 23.13 & -0.65 & 25.44 & 29.28 & 43.06 & 40.05 & 35.74 & 37.66 \\
\hline 2007 & 6.79 & 6.14 & -0.53 & -1.29 & -5.26 & -3.56 & 5.38 & 6.00 & 10.39 & 3.77 & 4.65 & 14.56 & 0.45 & 7.70 & 13.30 & 0.93 & -1.72 \\
\hline 2008 & -44.37 & -42.23 & -38.39 & -34.99 & -35.73 & -40.02 & -40.84 & -38.08 & -35.86 & -36.76 & -54.25 & -37.56 & -35.27 & -37.74 & -44.84 & -38.73 & -34.28 \\
\hline 2009 & 21.13 & 27.55 & 23.18 & 18.28 & 16.24 & 25.09 & 27.41 & 24.30 & 14.39 & 22.39 & -14.27 & -8.58 & 6.63 & 15.69 & 28.26 & 27.21 & 28.07 \\
\hline 2010 & -5.80 & 9.81 & 10.07 & 13.93 & 6.58 & 27.50 & 10.47 & 15.65 & -5.52 & 10.56 & -1.18 & 10.43 & 6.50 & 11.68 & 19.46 & 14.24 & 9.67 \\
\hline 2011 & -18.41 & -13.60 & -3.03 & -0.10 & -6.03 & -1.66 & -10.83 & 0.13 & 1.84 & 11.12 & -12.02 & -4.91 & -0.27 & -10.86 & -9.52 & -7.35 & -4.47 \\
\hline 2012 & 11.21 & 23.67 & 27.37 & 31.00 & 30.69 & 33.78 & 23.81 & 29.49 & 31.38 & 21.37 & 42.10 & 34.03 & 25.93 & 27.38 & 38.51 & 29.99 & 25.02 \\
\hline 2013 & 17.94 & 17.65 & 3.13 & 3.21 & 5.10 & 22.09 & 16.13 & 17.38 & 2.55 & 13.42 & 18.21 & 12.20 & 3.10 & 3.59 & 9.55 & 17.88 & 13.47 \\
\hline 2014 & 1.20 & 2.69 & 8.33 & 9.67 & 8.81 & 11.36 & 4.51 & 10.77 & 13.37 & 9.64 & -25.91 & 11.57 & 11.00 & 14.41 & 11.04 & 6.66 & 9.44 \\
\hline 2015 & 4.69 & 8.67 & 15.97 & 15.38 & 14.75 & 6.72 & 9.50 & 13.11 & 14.95 & 13.93 & -5.75 & 10.82 & 11.26 & 18.59 & 10.64 & 8.74 & 13.30 \\
\hline $\begin{array}{l}\text { Total Wealth } \\
\text { (Base 100 in } \\
\text { 01/02/2002) }\end{array}$ & 86.8 & 139.1 & 353.8 & 343.0 & 281.0 & 371.4 & 166.0 & 324.8 & 343.7 & 248.6 & 48.5 & 200.9 & 176.8 & 347.1 & 331.7 & 277.0 & 290.6 \\
\hline $\begin{array}{c}\text { Annualized } \\
\text { return }\end{array}$ & -1.00 & 2.39 & 9.45 & 9.20 & 7.66 & 9.82 & 3.69 & 8.78 & 9.22 & 6.72 & -5.04 & 5.11 & 4.16 & 9.30 & 8.94 & 7.55 & 7.92 \\
\hline
\end{tabular}


Table 5: VaR by years

\begin{tabular}{|c|c|c|c|c|c|c|c|c|c|c|c|c|c|c|c|c|c|}
\hline Year & Index & $1 / N$ & M-V & GMV & MAD & MDP & ERC & MTD & CVaR & MaxDD & AvDD & CDaR95 & MinCDaR95 & R-M & O-M & $\begin{array}{r}\text { Clayton } \\
\text { (MTD) }\end{array}$ & Beta \\
\hline 2002 & 3.951 & 3.899 & 2.134 & 2.146 & 2.071 & 2.153 & 3.412 & 2.496 & 2.173 & 3.722 & 4.163 & 2.978 & 2.566 & 2.367 & 2.441 & 2.268 & 2.223 \\
\hline 2003 & 2.698 & 2.688 & 2.077 & 1.337 & 1.352 & 1.368 & 2.243 & 1.714 & 1.393 & 1.654 & 1.807 & 1.995 & 2.234 & 1.865 & 1.658 & 1.627 & 1.646 \\
\hline 2004 & 1.403 & 1.410 & 0.888 & 1.079 & 1.073 & 1.056 & 1.155 & 1.006 & 1.138 & 1.253 & 1.557 & 1.475 & 1.124 & 1.100 & 1.302 & 0.985 & 0.932 \\
\hline 2005 & 1.050 & 1.048 & 1.280 & 1.686 & 1.651 & 1.611 & 1.033 & 1.336 & 1.784 & 2.302 & 2.527 & 2.329 & 2.060 & 1.296 & 1.988 & 1.384 & 1.222 \\
\hline 2006 & 1.436 & 1.446 & 1.525 & 1.531 & 1.540 & 1.484 & 1.388 & 1.393 & 1.423 & 1.389 & 2.820 & 1.476 & 1.381 & 1.461 & 1.583 & 1.402 & 1.430 \\
\hline 2007 & 1.587 & 1.606 & 1.649 & 1.744 & 2.046 & 2.038 & 1.608 & 1.512 & 1.294 & 1.319 & 2.807 & 1.379 & 1.494 & 1.419 & 1.420 & 1.920 & 1.909 \\
\hline 2008 & 4.210 & 4.037 & 3.140 & 3.281 & 3.250 & 3.320 & 3.899 & 3.431 & 3.239 & 3.704 & 5.054 & 3.859 & 3.584 & 3.508 & 3.816 & 3.379 & 3.355 \\
\hline 2009 & 2.770 & 2.616 & 1.918 & 2.360 & 1.898 & 2.490 & 2.421 & 2.380 & 1.951 & 2.416 & 3.517 & 2.861 & 2.291 & 2.409 & 2.957 & 2.073 & 2.002 \\
\hline 2010 & 2.450 & 2.100 & 1.500 & 1.488 & 1.374 & 1.822 & 1.966 & 1.778 & 1.520 & 1.819 & 2.296 & 1.767 & 1.667 & 1.697 & 1.992 & 1.723 & 1.653 \\
\hline 2011 & 3.009 & 2.816 & 2.051 & 2.070 & 2.094 & 2.681 & 2.622 & 2.385 & 2.074 & 1.787 & 3.301 & 2.714 & 2.432 & 2.883 & 3.269 & 2.529 & 2.217 \\
\hline 2012 & 2.059 & 1.829 & 1.562 & 1.536 & 1.524 & 1.576 & 1.687 & 1.669 & 1.534 & 1.506 & 2.448 & 1.653 & 1.464 & 1.642 & 1.676 & 1.644 & 1.459 \\
\hline 2013 & 1.599 & 1.511 & 1.777 & 1.797 & 1.702 & 1.522 & 1.473 & 1.497 & 1.866 & 1.450 & 2.267 & 1.804 & 1.846 & 1.925 & 1.844 & 1.492 & 1.464 \\
\hline 2014 & 1.730 & 1.564 & 1.473 & 1.469 & 1.467 & 1.581 & 1.513 & 1.541 & 1.482 & 1.567 & 2.861 & 1.900 & 1.509 & 1.565 & 1.675 & 1.495 & 1.425 \\
\hline 2015 & 2.289 & 2.063 & 1.667 & 1.677 & 1.658 & 2.206 & 2.017 & 1.743 & 2.307 & 1.866 & 3.349 & 2.370 & 2.298 & 2.402 & 2.458 & 2.025 & 1.874 \\
\hline$\underset{2002-2015}{\text { VaR }}$ & 2.455 & 2.336 & 1.815 & 1.860 & 1.819 & 1.993 & 2.161 & 1.927 & 1.859 & 2.107 & 3.021 & 2.268 & 2.073 & 2.052 & 2.247 & 1.922 & 1.843 \\
\hline
\end{tabular}

Table 6: CVaR by years

\begin{tabular}{|c|c|c|c|c|c|c|c|c|c|c|c|c|c|c|c|c|c|}
\hline Year & Index & $1 / \mathrm{N}$ & M-V & GMV & MAD & MDP & ERC & MTD & CVaR & MaxDD & AvDD & CDaR95 & MinCDaR95 & R-M & O-M & $\begin{array}{l}\text { Clayton } \\
\text { (MTD) }\end{array}$ & Beta \\
\hline 2002 & 4.916 & 4.848 & 2.672 & 2.686 & 2.591 & 2.688 & 4.245 & 3.117 & 2.726 & 4.643 & 5.193 & 3.718 & 3.203 & 2.960 & 3.053 & 2.832 & 2.775 \\
\hline 2003 & 3.402 & 3.390 & 2.622 & 1.686 & 1.705 & 1.728 & 2.828 & 2.161 & 1.757 & 2.083 & 2.277 & 2.504 & 2.805 & 2.360 & 2.087 & 2.050 & 2.074 \\
\hline 2004 & 1.767 & 1.774 & 1.140 & 1.389 & 1.381 & 1.358 & 1.462 & 1.285 & 1.465 & 1.613 & 1.997 & 1.893 & 1.438 & 1.410 & 1.668 & 1.263 & 1.193 \\
\hline 2005 & 1.336 & 1.336 & 1.629 & 2.124 & 2.081 & 2.030 & 1.313 & 1.687 & 2.246 & 2.890 & 3.171 & 2.924 & 2.589 & 1.642 & 2.503 & 1.747 & 1.547 \\
\hline 2006 & 1.815 & 1.831 & 1.951 & 1.959 & 1.969 & 1.897 & 1.763 & 1.778 & 1.822 & 1.764 & 3.540 & 1.875 & 1.758 & 1.868 & 2.020 & 1.790 & 1.826 \\
\hline 2007 & 1.998 & 2.021 & 2.069 & 2.187 & 2.562 & 2.555 & 2.022 & 1.903 & 1.634 & 1.658 & 3.528 & 1.744 & 1.875 & 1.788 & 1.794 & 2.411 & 2.394 \\
\hline 2008 & 5.230 & 5.016 & 3.894 & 4.077 & 4.038 & 4.119 & 4.845 & 4.261 & 4.024 & 4.607 & 6.273 & 4.800 & 4.458 & 4.358 & 4.734 & 4.194 & 4.171 \\
\hline 2009 & 3.496 & 3.308 & 2.428 & 2.979 & 2.397 & 3.148 & 3.063 & 3.009 & 2.462 & 3.053 & 4.401 & 3.583 & 2.882 & 3.038 & 3.737 & 2.626 & 2.537 \\
\hline 2010 & 3.070 & 2.644 & 1.892 & 1.880 & 1.730 & 2.310 & 2.477 & 2.245 & 1.902 & 2.292 & 2.873 & 2.227 & 2.098 & 2.140 & 2.517 & 2.175 & 2.084 \\
\hline 2011 & 3.758 & 3.521 & 2.571 & 2.598 & 2.622 & 3.364 & 3.280 & 2.994 & 2.605 & 2.252 & 4.132 & 3.402 & 3.052 & 3.608 & 4.095 & 3.167 & 2.778 \\
\hline 2012 & 2.595 & 2.316 & 1.984 & 1.953 & 1.939 & 2.006 & 2.138 & 2.120 & 1.952 & 1.909 & 3.108 & 2.103 & 1.859 & 2.084 & 2.135 & 2.089 & 1.853 \\
\hline 2013 & 2.023 & 1.912 & 2.233 & 2.258 & 2.141 & 1.930 & 1.863 & 1.894 & 2.344 & 1.831 & 2.862 & 2.276 & 2.320 & 2.419 & 2.324 & 1.889 & 1.849 \\
\hline 2014 & 2.172 & 2.965 & 1.856 & 1.853 & 1.849 & 1.995 & 1.903 & 1.944 & 1.875 & 1.975 & 3.562 & 2.395 & 1.903 & 1.977 & 2.112 & 1.882 & 1.797 \\
\hline 2015 & 2.878 & 2.597 & 2.106 & 2.118 & 2.094 & 2.775 & 2.540 & 2.199 & 2.909 & 2.355 & 4.199 & 2.984 & 2.895 & 3.032 & 3.096 & 2.549 & 2.364 \\
\hline$\underset{2002-2015}{\text { CVaR }}$ & 3.081 & 2.935 & 2.287 & 2.342 & 2.290 & 2.510 & 2.715 & 2.427 & 2.341 & 2.651 & 3.788 & 2.852 & 2.605 & 2.584 & 2.829 & 2.420 & 2.321 \\
\hline
\end{tabular}


Table 7: Sharpe ratios by years

\begin{tabular}{|c|c|c|c|c|c|c|c|c|c|c|c|c|c|c|c|c|c|}
\hline Year & Index & $1 / N$ & M-V & GMV & MAD & MDP & ERC & MTD & CVaR & MaxDD & AvDD & CDaR95 & MinCDaR95 & R-M & O-M & $\begin{array}{c}\text { Clayton } \\
\text { (MTD) }\end{array}$ & Beta \\
\hline 2002 & -0.998 & -1.054 & -0.281 & -0.379 & -0.388 & -0.616 & -1.025 & -0.621 & -0.033 & -0.756 & -0.757 & -0.645 & -0.672 & -0.439 & -0.435 & -0.633 & -0.650 \\
\hline 2003 & 0.552 & 0.627 & 0.773 & 0.708 & 0.677 & 0.888 & 0.613 & 0.593 & 0.637 & 0.477 & 0.524 & -0.025 & 0.065 & 1.168 & 0.445 & 0.542 & 0.522 \\
\hline 2004 & 0.479 & 0.384 & 3.099 & 3.559 & 3.535 & 3.382 & 1.181 & 2.368 & 3.470 & 3.549 & 3.186 & 3.281 & 2.602 & 2.921 & 2.819 & 2.840 & 2.757 \\
\hline 2005 & 1.828 & 2.078 & 1.956 & 0.537 & 0.601 & 0.557 & 1.774 & 0.835 & 0.426 & 0.018 & -0.072 & 0.014 & 0.175 & 1.267 & 0.403 & 0.849 & 1.194 \\
\hline 2006 & 0.962 & 1.208 & 2.752 & 2.755 & 2.690 & 2.604 & 1.633 & 2.436 & 2.778 & 1.574 & -0.023 & 1.626 & 1.976 & 2.687 & 2.332 & 2.348 & 2.420 \\
\hline 2007 & 0.420 & 0.376 & -0.032 & -0.074 & -0.259 & -0.175 & 0.329 & 0.390 & 0.777 & 0.283 & 0.163 & 1.014 & 0.030 & 0.531 & 0.904 & 0.048 & -0.090 \\
\hline 2008 & -1.113 & -1.103 & -1.300 & -1.122 & -1.159 & -1.281 & -1.103 & -1.172 & -1.168 & -1.040 & -1.142 & -1.020 & -1.030 & -1.134 & -1.250 & -1.214 & -1.072 \\
\hline 2009 & 0.738 & 1.009 & 1.154 & 0.750 & 0.827 & 0.967 & 1.083 & 0.980 & 0.715 & 0.892 & -0.411 & -0.302 & 0.285 & 0.633 & 0.918 & 1.249 & 1.331 \\
\hline 2010 & -0.238 & 0.457 & 0.654 & 0.903 & 0.470 & 1.428 & 0.520 & 0.850 & -0.368 & 0.566 & -0.051 & 0.576 & 0.383 & 0.669 & 0.940 & 0.800 & 0.571 \\
\hline 2011 & -0.630 & -0.494 & -0.149 & -0.004 & -0.292 & -0.062 & -0.421 & 0.005 & 0.088 & 0.609 & -0.370 & -0.182 & -0.011 & -0.383 & -0.295 & -0.295 & -0.203 \\
\hline 2012 & 0.531 & 1.232 & 1.645 & 1.881 & 1.876 & 1.990 & 1.339 & 1.659 & 1.904 & 1.346 & 1.616 & 1.916 & 1.662 & 1.570 & 2.123 & 1.709 & 1.611 \\
\hline 2013 & 1.075 & 1.118 & 0.175 & 0.177 & 0.296 & 1.376 & 1.050 & 1.111 & 0.136 & 0.893 & 0.777 & 0.658 & 0.166 & 0.184 & 0.506 & 1.145 & 0.888 \\
\hline 2014 & 0.069 & 0.170 & 0.553 & 0.641 & 0.586 & 0.698 & 0.294 & 0.679 & 1.121 & 0.600 & -0.945 & 0.593 & 0.708 & 0.888 & 0.641 & 0.437 & 0.645 \\
\hline 2015 & 0.220 & 0.413 & 0.924 & 0.885 & 0.859 & 0.300 & 0.462 & 0.730 & 0.631 & 0.725 & -0.172 & 0.448 & 0.480 & 0.750 & 0.424 & 0.424 & 0.690 \\
\hline $\begin{array}{c}\text { Sharpe Ratio } \\
\text { 2002-2015 }\end{array}$ & -0.041 & 0.101 & 0.509 & 0.484 & 0.413 & 0.482 & 0.169 & 0.446 & 0.485 & 0.314 & -0.167 & 0.222 & 0.198 & 0.444 & 0.390 & 0.386 & 0.421 \\
\hline $\begin{array}{l}\text { P-value } \\
\text { respect to the } \\
\text { Index }\end{array}$ & 1.000 & 0.429 & 0.015 & 0.038 & 0.070 & 0.035 & 0.256 & 0.025 & 0.036 & 0.137 & 0.712 & 0.277 & 0.311 & 0.038 & 0.095 & 0.054 & 0.030 \\
\hline Significance & $\ldots$ & $\ldots$ & $* *$ & $* *$ & $*$ & $* *$ & $\ldots$ & $* *$ & $* *$ & $\cdots$ & $\cdots$ & $\cdots$ & $\cdots$ & $* *$ & $*$ & $* *$ & $* *$ \\
\hline $\begin{array}{l}\text { P-value } \\
\text { respect to the } \\
\text { 1/N strategy }\end{array}$ & 0.429 & 1.000 & 0.012 & 0.049 & 0.093 & 0.023 & 0.360 & 0.009 & 0.053 & 0.266 & 0.321 & 0.523 & 0.606 & 0.041 & 0.135 & 0.021 & 0.012 \\
\hline Significance & $\ldots$ & $\ldots$ & $* *$ & $* *$ & $*$ & $* *$ & ... & $* * *$ & $*$ & $\ldots$ & $\ldots$ & $\ldots$ & $\ldots$ & $* *$ & $\ldots$ & $* *$ & $* *$ \\
\hline
\end{tabular}

Table 8: Diversification ratios by years

\begin{tabular}{|c|c|c|c|c|c|c|c|c|c|c|c|c|c|c|c|c|}
\hline Year & $1 / N$ & M-V & GMV & MAD & MDP & ERC & MTD & CVaR & MaxDD & AvDD & CDaR95 & MinCDaR95 & R-M & O-M & $\begin{array}{l}\text { Clayton } \\
\text { (MTD) }\end{array}$ & Beta \\
\hline 2002 & 1.358 & 1.642 & 1.637 & 1.667 & 1.658 & 1.417 & 1.531 & 1.618 & 1.242 & 1.000 & 1.288 & 1.534 & 1.556 & 1.439 & 1.567 & 1.555 \\
\hline 2003 & 1.382 & 1.446 & 1.778 & 1.782 & 1.792 & 1.472 & 1.631 & 1.746 & 1.560 & 1.000 & 1.451 & 1.384 & 1.512 & 1.437 & 1.637 & 1.622 \\
\hline 2004 & 1.502 & 1.732 & 1.748 & 1.757 & 1.798 & 1.653 & 1.795 & 1.517 & 1.516 & 1.000 & 1.291 & 1.655 & 1.706 & 1.512 & 1.876 & 1.847 \\
\hline 2005 & 1.659 & 1.591 & 1.752 & 1.768 & 1.836 & 1.810 & 1.900 & 1.676 & 1.376 & 1.000 & 1.275 & 1.549 & 1.564 & 1.472 & 1.928 & 1.937 \\
\hline 2006 & 1.516 & 1.509 & 1.506 & 1.517 & 1.619 & 1.568 & 1.669 & 1.437 & 1.402 & 1.191 & 1.507 & 1.416 & 1.596 & 1.623 & 1.684 & 1.619 \\
\hline 2007 & 1.540 & 1.558 & 1.549 & 1.527 & 1.584 & 1.554 & 1.623 & 1.500 & 1.450 & 1.000 & 1.401 & 1.463 & 1.442 & 1.466 & 1.625 & 1.562 \\
\hline 2008 & 1.306 & 1.424 & 1.347 & 1.363 & 1.505 & 1.319 & 1.396 & 1.380 & 1.209 & 1.238 & 1.212 & 1.206 & 1.323 & 1.454 & 1.455 & 1.383 \\
\hline 2009 & 1.414 & 1.445 & 1.508 & 1.503 & 1.607 & 1.468 & 1.652 & 1.342 & 1.421 & 1.000 & 1.221 & 1.451 & 1.304 & 1.487 & 1.623 & 1.632 \\
\hline 2010 & 1.277 & 1.312 & 1.348 & 1.395 & 1.423 & 1.303 & 1.389 & 1.311 & 1.219 & 1.000 & 1.283 & 1.234 & 1.243 & 1.305 & 1.437 & 1.358 \\
\hline 2011 & 1.237 & 1.261 & 1.273 & 1.249 & 1.334 & 1.260 & 1.365 & 1.250 & 1.206 & 1.000 & 1.179 & 1.108 & 1.268 & 1.203 & 1.328 & 1.310 \\
\hline 2012 & 1.403 & 1.341 & 1.340 & 1.346 & 1.615 & 1.456 & 1.555 & 1.288 & 1.278 & 1.183 & 1.370 & 1.269 & 1.344 & 1.361 & 1.559 & 1.481 \\
\hline 2013 & 1.481 & 1.360 & 1.290 & 1.374 & 1.734 & 1.521 & 1.679 & 1.250 & 1.294 & 1.205 & 1.322 & 1.245 & 1.307 & 1.255 & 1.668 & 1.505 \\
\hline 2014 & 1.346 & 1.236 & 1.251 & 1.252 & 1.426 & 1.368 & 1.424 & 1.260 & 1.157 & 1.000 & 1.329 & 1.229 & 1.239 & 1.218 & 1.427 & 1.380 \\
\hline 2015 & 1.315 & 1.252 & 1.270 & 1.258 & 1.394 & 1.323 & 1.464 & 1.206 & 1.276 & 1.012 & 1.316 & 1.174 & 1.139 & 1.176 & 1.356 & 1.290 \\
\hline $\begin{array}{c}\text { Diversification } \\
2002-2015\end{array}$ & 1.410 & 1.436 & 1.471 & 1.483 & 1.595 & 1.464 & 1.577 & 1.413 & 1.329 & 1.059 & 1.318 & 1.351 & 1.396 & 1.386 & 1.584 & 1.534 \\
\hline
\end{tabular}


Table 9: Component numbers by portfolio and year

\begin{tabular}{|c|c|c|c|c|c|c|c|c|c|c|c|c|c|c|c|c|}
\hline Year & $1 / N$ & M-V & GMV & MAD & MDP & ERC & MTD & CVaR & MaxDD & AvDD & CDaR95 & MinCDaR95 & R-M & O-M & $\begin{array}{l}\text { Clayton } \\
\text { (MTD) }\end{array}$ & Beta \\
\hline 2002 & 44 & 22 & 22 & 18 & 24 & 44 & 31 & 18 & 6 & 1 & 4 & 11 & 9 & 7 & 22 & 21 \\
\hline 2003 & 45 & 13 & 14 & 13 & 21 & 45 & 30 & 12 & 10 & 1 & 7 & 11 & 8 & 5 & 22 & 22 \\
\hline 2004 & 48 & 10 & 10 & 10 & 15 & 48 & 24 & 10 & 3 & 1 & 3 & 7 & 10 & 7 & 24 & 24 \\
\hline 2005 & 49 & 10 & 11 & 11 & 15 & 49 & 20 & 7 & 5 & 1 & 4 & 5 & 6 & 5 & 24 & 24 \\
\hline 2006 & 49 & 12 & 11 & 12 & 19 & 49 & 23 & 10 & 9 & 2 & 7 & 7 & 9 & 8 & 24 & 24 \\
\hline 2007 & 49 & 18 & 19 & 18 & 19 & 49 & 26 & 13 & 9 & 1 & 7 & 8 & 8 & 8 & 24 & 24 \\
\hline 2008 & 49 & 19 & 16 & 17 & 20 & 49 & 27 & 12 & 7 & 2 & 6 & 11 & 11 & 7 & 24 & 24 \\
\hline 2009 & 50 & 12 & 11 & 15 & 13 & 50 & 17 & 7 & 9 & 1 & 4 & 6 & 7 & 4 & 25 & 25 \\
\hline 2010 & 50 & 11 & 11 & 13 & 18 & 50 & 18 & 8 & 4 & 1 & 8 & 5 & 6 & 5 & 24 & 24 \\
\hline 2011 & 50 & 9 & 11 & 9 & 17 & 50 & 17 & 11 & 3 & 1 & 3 & 2 & 9 & 6 & 25 & 25 \\
\hline 2012 & 50 & 8 & 8 & 8 & 14 & 50 & 23 & 7 & 5 & 2 & 5 & 6 & 10 & 5 & 25 & 25 \\
\hline 2013 & 50 & 7 & 7 & 8 & 12 & 50 & 16 & 5 & 4 & 2 & 4 & 5 & 6 & 3 & 25 & 25 \\
\hline 2014 & 50 & 11 & 10 & 11 & 13 & 50 & 21 & 6 & 5 & 1 & 4 & 7 & 6 & 4 & 25 & 25 \\
\hline 2015 & 50 & 17 & 15 & 18 & 19 & 50 & 26 & 10 & 9 & 2 & 9 & 10 & 8 & 7 & 25 & 25 \\
\hline $\begin{array}{l}\text { Average assets } \\
\text { in portfolio }\end{array}$ & 48.8 & 12.8 & 12.6 & 12.9 & 17.1 & 48.8 & 22.8 & 9.7 & 6.3 & 1.4 & 5.4 & 7.2 & 8.1 & 5.8 & 24.1 & 24.1 \\
\hline Ratio & 1.00 & 0.27 & 0.26 & 0.37 & 0.35 & 1.00 & 0.47 & 0.20 & 0.13 & 0.03 & 0.11 & 0.15 & 0.17 & 0.12 & 0.50 & 0.50 \\
\hline
\end{tabular}

Table 10: Concentration ratios by years

\begin{tabular}{|c|c|c|c|c|c|c|c|c|c|c|c|c|c|c|c|c|}
\hline Year & $1 / N$ & M-V & GMV & MAD & MDP & ERC & MTD & CVaR & MaxDD & AvDD & CDaR95 & MinCDaR95 & R-M & O-M & $\begin{array}{c}\text { Clayton } \\
\text { (MTD) }\end{array}$ & Beta \\
\hline 2002 & 0.025 & 0.086 & 0.093 & 0.088 & 0.060 & 0.024 & 0.044 & 0.113 & 0.460 & 1.000 & 0.373 & 0.120 & 0.161 & 0.208 & 0.049 & 0.050 \\
\hline 2003 & 0.024 & 0.120 & 0.125 & 0.137 & 0.087 & 0.024 & 0.048 & 0.143 & 0.188 & 1.000 & 0.289 & 0.161 & 0.177 & 0.358 & 0.058 & 0.056 \\
\hline 2004 & 0.022 & 0.118 & 0.157 & 0.157 & 0.122 & 0.026 & 0.063 & 0.250 & 0.345 & 1.000 & 0.535 & 0.200 & 0.143 & 0.262 & 0.069 & 0.067 \\
\hline 2005 & 0.021 & 0.203 & 0.195 & 0.193 & 0.146 & 0.031 & 0.084 & 0.228 & 0.436 & 1.000 & 0.546 & 0.273 & 0.252 & 0.345 & 0.094 & 0.076 \\
\hline 2006 & 0.021 & 0.196 & 0.195 & 0.176 & 0.098 & 0.025 & 0.082 & 0.258 & 0.293 & 0.687 & 0.208 & 0.247 & 0.139 & 0.187 & 0.063 & 0.077 \\
\hline 2007 & 0.021 & 0.078 & 0.074 & 0.079 & 0.080 & 0.022 & 0.051 & 0.126 & 0.180 & 1.000 & 0.200 & 0.204 & 0.198 & 0.202 & 0.059 & 0.063 \\
\hline 2008 & 0.021 & 0.079 & 0.107 & 0.100 & 0.070 & 0.021 & 0.060 & 0.121 & 0.254 & 0.589 & 0.237 & 0.218 & 0.135 & 0.249 & 0.048 & 0.055 \\
\hline 2009 & 0.022 & 0.206 & 0.178 & 0.118 & 0.152 & 0.021 & 0.082 & 0.267 & 0.182 & 1.000 & 0.503 & 0.226 & 0.347 & 0.260 & 0.049 & 0.059 \\
\hline 2010 & 0.021 & 0.143 & 0.133 & 0.122 & 0.120 & 0.021 & 0.086 & 0.154 & 0.266 & 1.000 & 0.191 & 0.231 & 0.265 & 0.324 & 0.048 & 0.052 \\
\hline 2011 & 0.022 & 0.162 & 0.165 & 0.185 & 0.122 & 0.021 & 0.081 & 0.199 & 0.423 & 1.000 & 0.404 & 0.513 & 0.149 & 0.238 & 0.045 & 0.047 \\
\hline 2012 & 0.022 & 0.267 & 0.254 & 0.245 & 0.103 & 0.021 & 0.078 & 0.297 & 0.323 & 0.583 & 0.221 & 0.243 & 0.237 & 0.228 & 0.048 & 0.050 \\
\hline 2013 & 0.021 & 0.252 & 0.297 & 0.210 & 0.125 & 0.022 & 0.088 & 0.349 & 0.362 & 0.528 & 0.315 & 0.344 & 0.236 & 0.386 & 0.049 & 0.057 \\
\hline 2014 & 0.020 & 0.248 & 0.234 & 0.219 & 0.104 & 0.021 & 0.084 & 0.252 & 0.416 & 1.000 & 0.280 & 0.303 & 0.323 & 0.288 & 0.046 & 0.057 \\
\hline 2015 & 0.021 & 0.126 & 0.112 & 0.151 & 0.082 & 0.022 & 0.065 & 0.208 & 0.181 & 0.937 & 0.197 & 0.174 & 0.172 & 0.215 & 0.046 & 0.052 \\
\hline $\begin{array}{c}\text { Concentration } \\
2002-2015\end{array}$ & 0.022 & 0.163 & 0.166 & 0.156 & 0.105 & 0.023 & 0.071 & 0.212 & 0.308 & 0.880 & 0.321 & 0.247 & 0.210 & 0.268 & 0.055 & 0.058 \\
\hline
\end{tabular}


Figure 1: Returns by year of Euro Stoxx 50 index and 1/N, M-V, CVaR, GMV y MDP portfolios

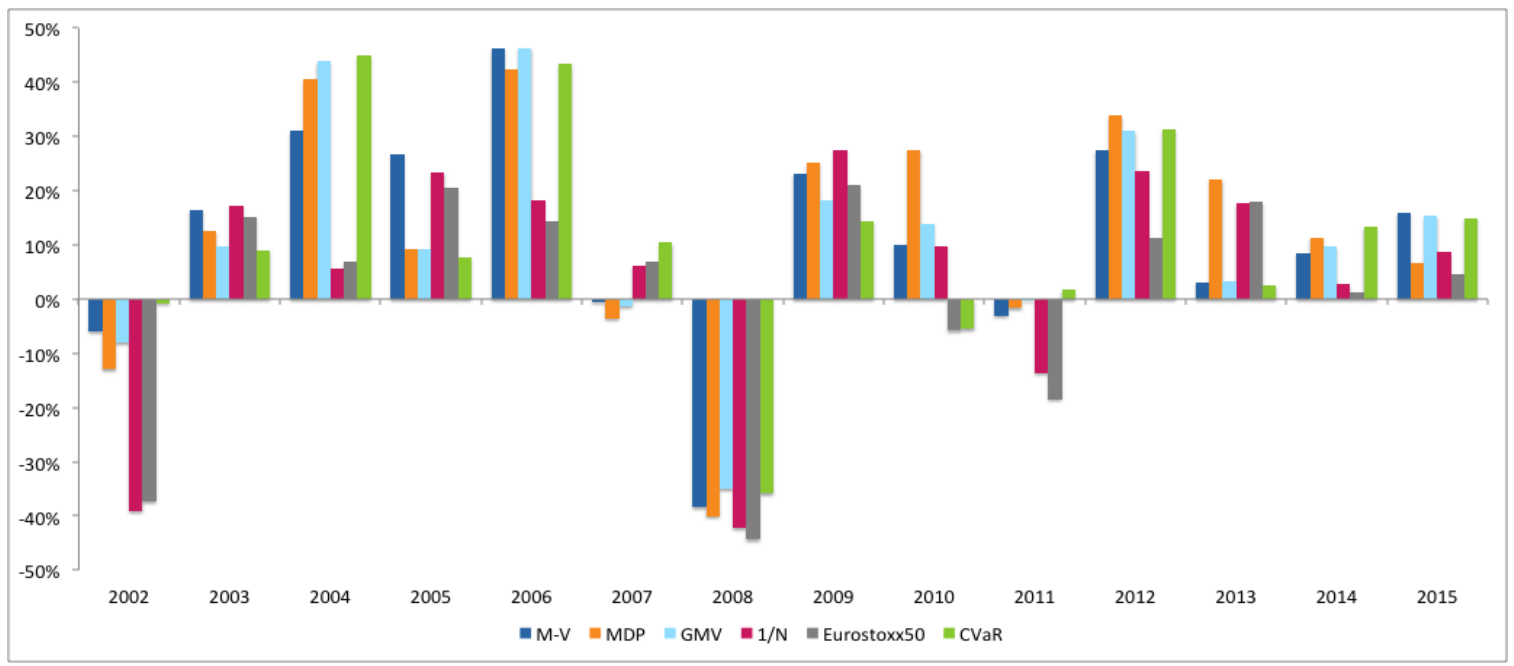


Figure 2: Accumulated wealth, 2002-2015 period

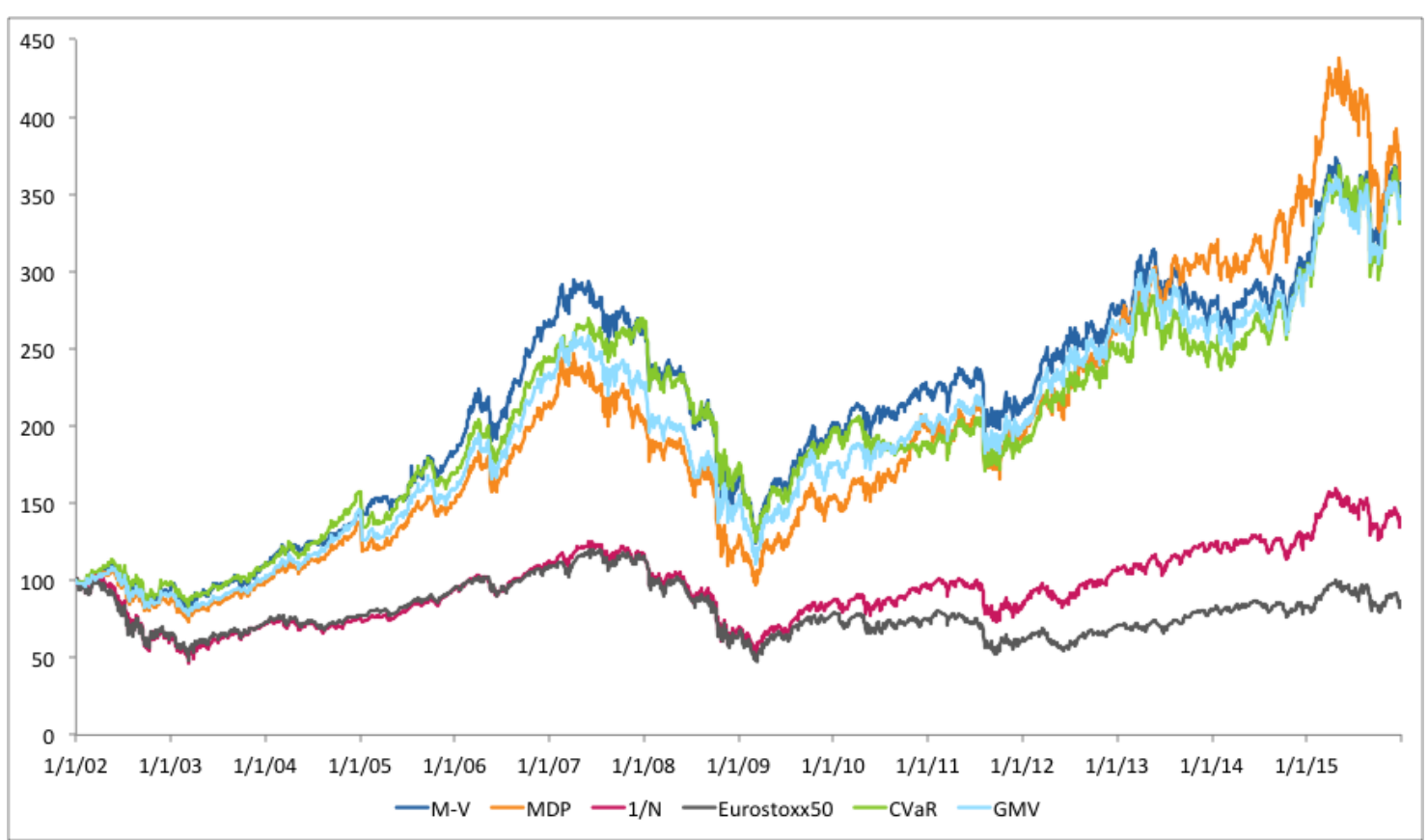

Accumulated wealth in the 2002-2015 time period. Base 100 in January 2nd 2002. We represent the accumulated wealth of an investor who invested 100 currency units on January 2nd 2002. We include the Euro Stoxx 50 index, the 1/N portfolio, the M-V portfolio, the MDP portfolio, the CVaR portfolio and the GMV portfolio. 


\section{Annex}

In this Annex we include two tables (Tables A1 and A2). Table A1 offers the assets name that we have considered for the portfolio construction in each period, while Table A2 reports seven descriptive statistic that provide information about the behaviour of the Euro Stoxx 50 index index and the 16 main models consider in this paper, while 


\section{Table A1: Assets used in the portfolio construction by time period}

\begin{tabular}{ccc} 
Period & Asset number & \multicolumn{1}{c}{ Asset name } \\
\hline & & Air Liquide, Allianz, ASML, Assicurazioni, AXA, BASF, Bayer, BBVA, \\
& & Santander, BMW, BNP, Carrefour, Daimler, Danone, Deutsche Bank, Deutsche \\
$02 / 01 / 2002$ & & Telekom, EON, Eni, Essilor, Societe Generale, Iberdrola, ING, Intensa, L'oreal, \\
$30 / 12 / 2002$ & LVMH, Muenchener, Nokia, Orange, Philips, Repsol, RWE, Saint Gobain, Sanofi, \\
& SAP, Schneider, Siemens, Telefonica, Total, Unibail-Rodamco, Unicredit, Unilever, \\
& Vinci, Vivendi, Volkswagen.
\end{tabular}

Air Liquide, Allianz, ASML, Assicurazioni, AXA, BASF, Bayer, BBVA, LVMH, Muenchener, Nokia, Orange, Philips, Repsol, RWE, Saint Gobain, Sanofi, SAP, Schneider, Siemens, Telefonica, Total, Unibail-Rodamco, Unicredit, Unilever, Vinci, Vivendi, Volkswagen, Enel.

Air Liquide, Allianz, ASML, Assicurazioni, AXA, BASF, Bayer, BBVA, $30 / 12 / 2004$ Santander, BMW, BNP, Carrefour, Daimler, Danone, Deutsche Bank, Deutsche Telekom, EON, Eni, Essilor, Societe Generale, Iberdrola, ING, Intensa, L'oreal, LVMH, Muenchener, Nokia, Orange, Philips, Repsol, RWE, Saint Gobain, Sanofi, SAP, Schneider, Siemens, Telefonica, Total, Unibail-Rodamco, Unicredit, Unilever, Vinci, Vivendi, Volkswagen, Enel, Airbus, Deutsche Post, Anheuser-Busch.

$03 / 01 / 2005$

$30 / 12 / 2005$

$02 / 01 / 2006$

$29 / 12 / 2006$

$02 / 01 / 2007$

$28 / 12 / 2007$

$02 / 01 / 2008$

$30 / 12 / 2008$

$02 / 01 / 2009$

$30 / 12 / 2009$

$02 / 01 / 2010$

$30 / 12 / 2010$

$04 / 01 / 2011$

$30 / 12 / 2011$

$03 / 01 / 2012$

$31 / 12 / 2012$

$02 / 01 / 2013$

$31 / 12 / 2013$

$02 / 01 / 2014$

$31 / 12 / 2014$

$02 / 01 / 2015$

$31 / 12 / 2015$
Air Liquide, Allianz, ASML, Assicurazioni, AXA, BASF, Bayer, BBVA, Santander, BMW, BNP, Carrefour, Daimler, Danone, Deutsche Bank, Deutsche Telekom, EON, Eni, Essilor, Societe Generale, Iberdrola, ING, Intensa, L'oreal, LVMH, Muenchener, Nokia, Orange, Philips, Repsol, RWE, Saint Gobain, Sanofi, SAP, Schneider, Siemens, Telefonica, Total, Unibail-Rodamco, Unicredit, Unilever, Vinci, Vivendi, Volkswagen, Enel, Airbus, Deutsche Post, Anheuser-Busch, Inditex. 
Table A2: Summary statistics of Euro Stoxx 50 index and portfolios

\begin{tabular}{|c|c|c|c|c|c|c|c|}
\hline Portfolios & Min & 1st Cuartil & Median & Mean & 3st Cuartil & $\operatorname{Max}$ & S.D. \\
\hline Index & -7.880 & -0.676 & 0.000 & 0.007 & 0.715 & 11.001 & 1.497 \\
\hline $1 / \mathrm{N}$ & -7.622 & -0.634 & 0.025 & 0.019 & 0.704 & 10.007 & 1.432 \\
\hline $\mathrm{M}-\mathrm{V}$ & -5.890 & -0.516 & 0.046 & 0.041 & 0.631 & 7.377 & 1.129 \\
\hline GMV & -10.786 & -0.530 & 0.050 & 0.040 & 0.649 & 8.052 & 1.155 \\
\hline MAD & -10.507 & -0.517 & 0.041 & 0.035 & 0.630 & 7.655 & 1.127 \\
\hline MDP & -10.135 & -0.559 & 0.070 & 0.044 & 0.676 & 7.235 & 1.238 \\
\hline ERC & -7.418 & -0.593 & 0.031 & 0.023 & 0.665 & 9.763 & 1.328 \\
\hline MTD & -7.775 & -0.528 & 0.055 & 0.039 & 0.653 & 9.188 & 1.196 \\
\hline $\mathrm{CVaR}$ & -11.580 & -0.510 & 0.052 & 0.040 & 0.655 & 9.570 & 1.155 \\
\hline MaxDD & -15.239 & -0.571 & 0.052 & 0.033 & 0.680 & 10.536 & 1.301 \\
\hline AvDD & -16.672 & -0.890 & 0.000 & -0.003 & 0.943 & 12.797 & 1.835 \\
\hline CDaR95 & -15.468 & -0.617 & 0.017 & 0.029 & 0.742 & 10.395 & 1.397 \\
\hline MinCDaR95 & -13.578 & -0.577 & 0.019 & 0.024 & 0.692 & 9.237 & 1.275 \\
\hline R-M & -6.006 & -0.580 & 0.043 & 0.042 & 0.681 & 9.602 & 1.274 \\
\hline O-M & -12.829 & -0.601 & 0.045 & 0.043 & 0.769 & 7.741 & 1.392 \\
\hline Clayton (MTD) & -8.175 & -0.525 & 0.056 & 0.035 & 0.648 & 7.444 & 1.190 \\
\hline Beta & -6.798 & -0.511 & 0.044 & 0.036 & 0.622 & 9.363 & 1.143 \\
\hline
\end{tabular}




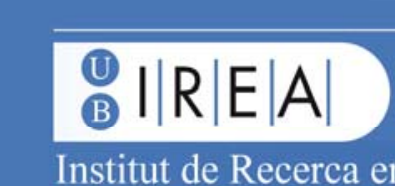

